\title{
AGAO FUNGICIDA DO INSETICIDA CARTAP SOBRE A FERRUGEM DO FEIJOEIRO
}

\author{
MARGARIDA FUMIKO ITO
}

Tese apresentada à Escola Superior de Agricultura "Luiz de Queiroz", da Universidade de São Paulo, para obtenção do título de Doutor em Agronomia. Área de concentração: Fitopatologia.

PIRACICABA

Estado de São Paulo - Brasil

Novembro - 1993 
Ficha catalografica preparada pela Seça de Livros da Divisăo de Biblioteca e Documentaçăo - PCLQ/USP

$189 a$

Ito, Margarida Fumiko

Açăo fungicida do inseticida Cartap sobre a ferrugem do feijoeiro. Piracicaba, 1993.

$$
\text { P. }
$$

Tese - ESALQ

Bibliografia

1. Feijă - Doença 2. Ferrugen do feijão Controle quimico 3 . Inseticida em feijă I. Escola Superior de Agricultura Luiz de Queiraz, Piracicaba

$$
\text { CDD } 635.652
$$




\title{
AGAO FUNGICIDA DO INSETICIDA CARTAP SOBRE A FERRUGEM DO FEIJOEIRO
}

\author{
MARGARIDA FUMIKO ITO
}

Orientador: Prof. Dr. ARMANDO BERGAMIN FILHO

Tese apresentada a Escola Superior de Agricultura "Luiz de Queiroz", da Universidade de São Paulo, para obtenção do título de Doutor em Agronomia. Área de concentração: Fitopatologia.

\author{
PIRACICABA \\ Estado de São Paulo - Brasil \\ Novembro - 1993
}




\section{AÇÃO FUNGICIDA DO INSETICIDA CARTAP SOBRE A FERRUGEM DO FEIJOEIRO}

Margarida Fumiko Ito

Aprovada em: 24.02.1994

Comissão Julgadora:

Dr. Osvaldo Paradela Filho

IAC/CPA/SAA

Prof. Dr. Antonio Carlos Maringoni

FCA/UNESP

Prof. Dr. Hiroshi Kimati

ESALQ/USP

Prof Dra Lilian Amorim

ESALQ/USP

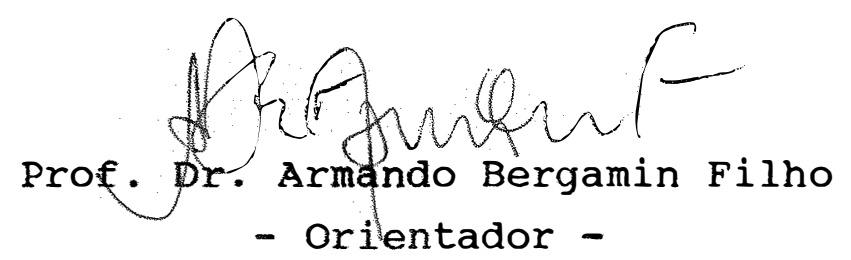


DEUS,

pelo milagre,

o agradecimento supremo!!! 
Shoiti e Kimie, meus pais amados, Que com sacrificios, Possibilitaram-me os estudos,

Shuraharu, Toru, Masato ("in memorian")

Laura, Hélio e Mário, meus irmãos, que esforços não medem, Para dar-nos as mãos,
A todos, o meu carinho, A minha gratidão!

Umberto, Yuri, Humberto e Marcio Pela alegria de tê-los, Pela colaboração e compreensão, com todo amor e carinho,

A minha dedicação! 


\section{AGRADECIMENTOS}

Expresso minha sincera gratidão,

Ao Instituto Agronômico de Campinas/IAC, à Seção de Fitopatologia/IAC, à Escola Superior de Agricultura "Luiz de Queiroz"/ESALQ e ao Departamento de Fitopatologia/ ESALQ, pela oportunidade concedida para a realização do Curso de PósGraduação e do presente trabalho;

Ao CNPq e CAPES, pelas bolsas de estudo;

Ao Prof. Dr. Armando Bergamin Filho, pela valiosa orientação e apoio;

Ao Prof. Dr. Hiroshi Kimati, pela atenção e sugestões ;

Ao Pesquisador Dr. Osvaldo Paradela Filho, pelas sugestões, revisão dos originais e apoio em todos os momentos;

Aos pesquisadores MS Christina Dudienas, Hélio Masatoshi Tukamoto, MS Jairo Lopes de Castro, Dra Maria Aparecida de Souza Tanaka e Dr. Valdir Atsushi Yuki, pelo apoio e colaboração na realização do trabalho;

Ao pesquisador Dr. Jaciro Soave, pela revisão do Summary;

Aos pesquisadores $\mathrm{Dr}$. Ivan José Antunes Ribeiro e Drs Maria Angélica Pizzinatto, pelo apoio; 
Ao Dr. Mauro Hideo Sugimori, Chefe da Seção de Fitopatologia/IAC e Dr. Sérgio Almeida de Moraes, Diretor da Divisão de Biologia Fitotécnica/IAC, pelo apoio e incentivo;

Aos professores, colegas e funcionários do Departamento de Fitopatologia/ESALQ, pelos ensinamentos e colaboração durante o Curso;

Aos funcionários da Seção de Fitopatologia/ IAC, pelos valiosos auxílios na realização do trabalho;

À IHARABRAS S.A. INDÚSTRIAS QUIMICAS, pelo apoio durante a realização da pesquisa;

A todos aqueles que contribuíram na realização deste trabalho. 
SUMÁRIO

Página

LISTA DE TABELAS ........................

LISTA DE FIGURAS ..................... xii

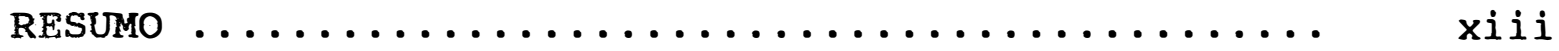

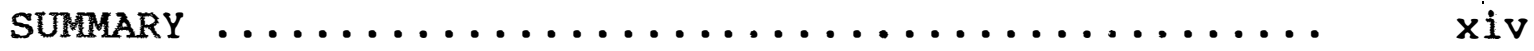

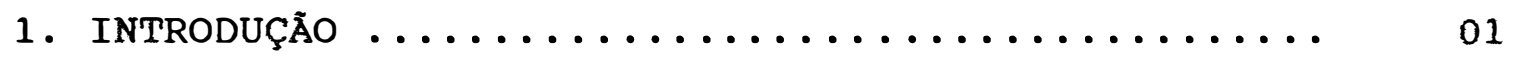

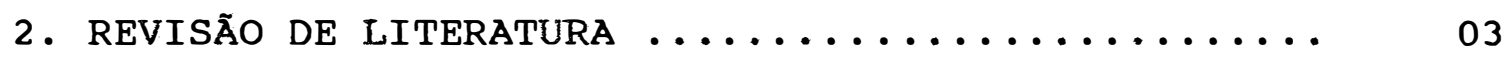

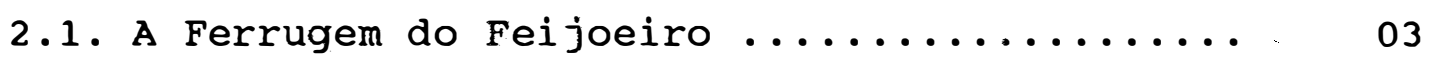

2.2. Controle da Ferrugem do Feijoeiro ......... 06

3. MATERIAL E mÉtodos ........................ 21

3.1. Experimentos de Laboratório ............. 21

3.1.1. Ação fungicida do cartap sobre uredosporos de $U$. appendiculatus ....... 21

3.1.2. Ação fungicida do cartap sobre uredosporos de $U$. appendiculatus, "in

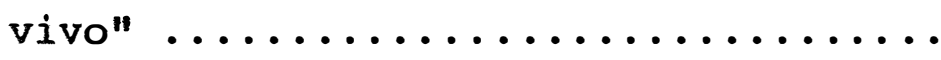

3.1.3. Ação do cartap sobre "flecks" e uredosporos de $U$. appendiculatus ......

3.1.4. Ação preventiva do cartap sobre $U$.

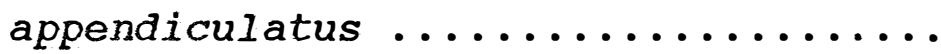

3.1.5. Ação curativa do cartap sobre $U$. appendiculatus .............. 24

3.1.6. Ação erradicante do cartap sobre $U$. appendiculatus, em associação com

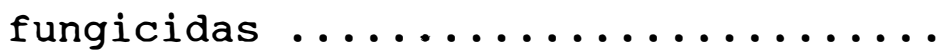

3.2. Experimentos de Campo ................

3.2.1. Efeito fungicida do cartap sobre a 


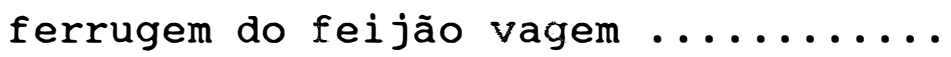

3.2.2. Efeito fungicida do cartap sobre a ferrugem do feijoeiro, na safra das

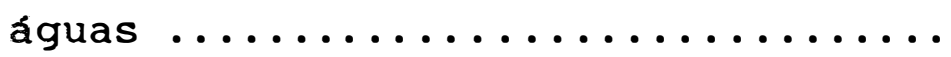

3.2.3. Efeito fungicida do cartap sobre a ferrugem do feijoeiro, na safra da

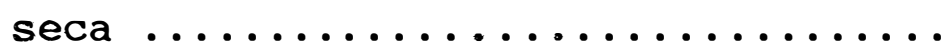

4. RESULTADOS E DISCUSSÃo ...................

4.1. Experimentos de Laboratório .............

4.1.1. Ação fungicida do cartap sobre uredosporos de $U$. appendiculatus ......

4.1.2. Ação fungicida do cartap sobre uredosporos de $U$. appendiculatus, "in

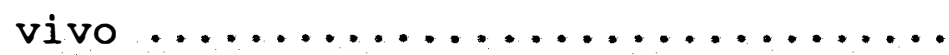

4.1.3. Ação do cartap sobre "flecks" e uredosporos de $U$. appendiculatus .......

4.1.4. Ação preventiva do cartap sobre $U$.

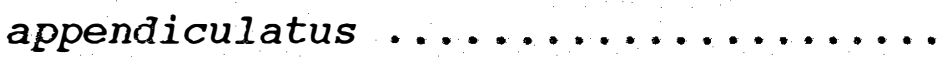

4.1.5. Ação curativa do cartap sobre $U$.

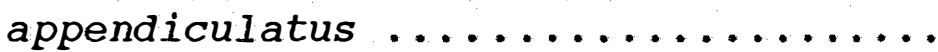

4.1.6. Ação erradicante do cartap sobre $U$. appendiculatus, em associação com

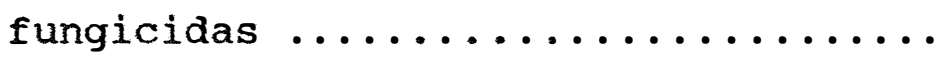

4.2. Experimentos de Campo ................

4.2.1. Efeito fungicida do cartap sobre a ferrugem do feijão vagem ...........

4.2.2. Efeito fungicida do cartap sobre a ferrugem do feijoeiro, na safra das

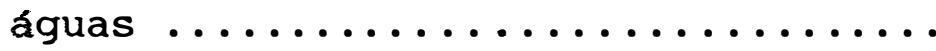

4.2.3. Efeito fungicida do cartap sobre a ferrugem do feijoeiro, na safra da

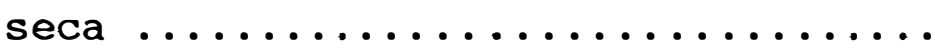


5. CONCLUSÕES $\ldots \ldots \ldots \ldots \ldots \ldots \ldots \ldots \ldots \ldots \ldots \ldots \ldots \ldots \ldots \ldots \ldots \ldots$ 


\section{LISTA DE TABELAS}

TABELA $\mathbf{N}^{\circ}$

Página

1 Efeito preventivo do inseticida cartap sobre $o$ número de pústulas de $U$. appendicula-

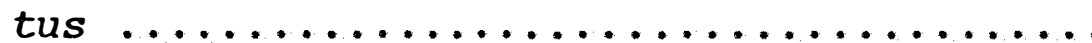

2 Efeito do inseticida cartap sobre $U$. appendiculatus, em feijoeiro cv. Rosinha G-2, em associação com fungicidas, 7 e 14 dias após

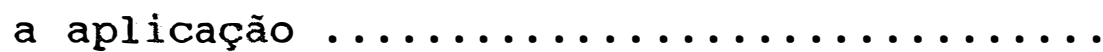

3 Efeito preventivo dos defensivos agrícolas sobre a ferrugem do feijão vagem ........

4 Efeito erradicante dos defensivos agrícolas sobre a ferrugem do feijão vagem ........

5 Efeito dos defensivos agrícolas sobre a incidência da ferrugem nas vagens, na quarta

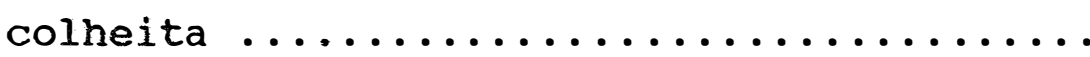

6 Efeito dos defensivos agrícolas na produção e peso de vagens de feijão vagem .........

7 Efeito dos defensivos agrícolas sobre a ferrugem do feijoeiro, cultivar Aroana 80,

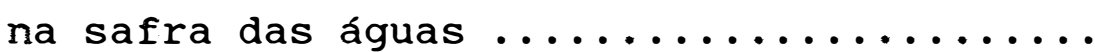

8 Efeito dos defensivos agrícolas sobre o peso de 100 sementes de feijão, cultivar Aroana 80 , na safra das águas .......... 
9 Efeito dos defensivos agrícolas na produtividade do feijoeiro, cultivar Aroana 80 , na

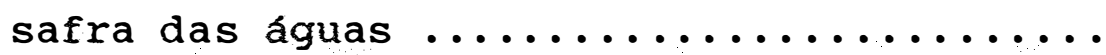

10 Efeito dos defensivos agricolas sobre a ferrugem do feijoeiro, cultivar Aroana 80,

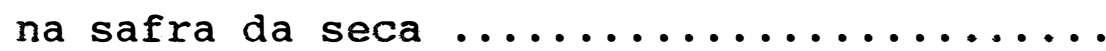

11 Efeito dos defensivos agrícolas sobre o peso de 100 sementes de feijão, cultivar Aroana 80 , na safra da seca ...........

12 Efeito dos defensivos agrícolas sobre a produtividade do feijoeiro, cultivar Aroana

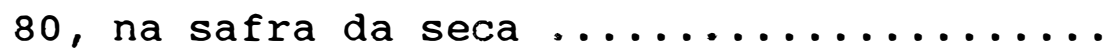




\section{LISTA DE FIGURAS}

FIGURA $\mathrm{N}^{\circ}$

Página

1 Pústulas de $U$. appendiculatus com uredosporos, inviáveis, sobre folha primária de

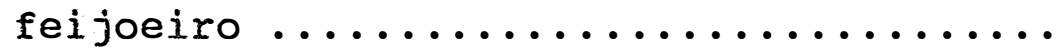

2 Folíolo de feijoeiro, após aplicação do cartap na fase de "fleck" da ferrugem, mostrando os pontos brancos e salientes, contituídos de uredosporos inviáveis ....

3 Efeito curativo do cartap sobre a ferrugem do feijoeiro. Desenvolvimento normal da ferrugem (Testemunha) e inviabilização dos uredosporos de $U$. appendiculatus

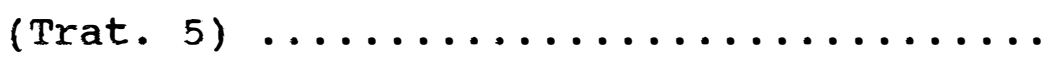




\title{
AÇÃO FUNGICIDA DO INSETICIDA CARTAP SOBRE A FERRUGEM DO FEIJOEIRO
}

\author{
Autora: Margarida Fumiko Ito \\ Orientador: Prof. Dr. Armando Bergamin Filho
}

\section{RBSUMO}

Foi estudada a ação fungicida do inseticida cartap sobre Uromyces appendiculatus, assim como as ações preventiva e curativa, em laboratório. Avaliou-se também a ação erradicante do cartap, em associação com outros fungicidas no controle da ferrugem do feijoeiro, em plantas do cultivar Rosinha G-2, sob condições de sala climatizada.

Foram desenvolvidos experimentos com a cultura do feijão vagem e feijão comum, para verificar a ação do cartap sobre $U$. appendiculatus, em condições de campo.

Foi constatada a ação fungicida do inseticida cartap a $U$. appendiculatus, através da inviabilização dos uredosporos, que apresentaram-se de coloração branca, assim como as ações preventiva e curativa, em laboratório. A ação erradicante foi observada quando cartap foi aplicado em associação com vários fungicidas.

Os resultados obtidos em laboratório foram confirmados nos experimentos de campo, nas culturas do feijão vagem e feijão comum.

Os efeitos apresentados pelo inseticida cartap sobre $U$. appendiculatus indicam que, com este produto, os agricultores têm uma garantia da cultura quanto à ferrugem do feijoeiro, pois esta doença poderá ser controlada, mesmo após seu estabelecimento. 
xiv

FUNGICIDAL ACTION OF CARTAP INSECTICIDE ON BEAN RUST

Author: Margarida Fumiko Ito

Adviser: Prof. Dr. Armando Bergamin Filho

SUMAARY

The fungicidal action of cartap insecticide on Uromyces appendiculatus was studied, in laboratory, as well as the preventive and curative actions. The eradicative action of cartap was also evaluated in association with several fungicides. These tests were conduced under controlled environmental conditions.

Experiments were also conduced in field conditions, with snap bean and dry bean, to verify the action of cartap on $U$. appendiculatus.

Is was found the fungicidal action of cartap insecticide on $U$. appendiculatus. The uredospores were inactivated and showed white colour.

The cartap insecticide presented preventive and curative effects in laboratory tests. The eradicative effect occurred when cartap was tested in association with fungicides.

The laboratory results were confirmed in field experiments on snap bean and dry bean crops.

The effects presented by cartap insecticide on $U$. appendiculatus show that with this chemical, the growers have security in producing good yield as so bean rust concern, because this disease will be controlled with success after its establishment. 


\section{INTRODUÇÃO}

A ferrugem do feijoeiro e do feijão vagem é causada por Uromyces appendiculatus (Pers.) LK. Este fungo, além de ter uma grande variabilidade patogênica (KIMATI, 1980), apresenta importância pela sua distribuição geográfica generalizada, podendo causar prejuízos na produção que chegam a 70\% (SARTORATO et al., 1983) até 100\% (NASSER et al., 1977).

A maioria dos cultivares de feijoeiro recomendada para o cultivo, pela Secretaria de Agricultura do Estado de São Paulo, apresenta resistência às raças de $U$. appendiculatus. Todavia, a grande variabilidade do patógeno tem inviabilizado o uso de cultivares resistentes, evidenciando a dificuldade do controle da doença somente por meio da resistência. O emprego de fungicidas, aliado à resistência genética dos cultivares de feijão, tem-se mostrado boa alternativa como medida de controle.

Na cultura do feijão vagem, a ferrugem também é considerada uma das principais doenças (FRENHANI et al., 1971; YAMAMOTO et al., 1971; CASTELLANE et al., 1988; TANAKA et al., 1991). Variedades comerciais não apresentam resistência ao 
patógeno, sendo necessário o emprego constante de fungicidas para se reduzir prejuizos na produção.

Algumas pesquisas têm demonstrado a eficácia de vários fungicidas sistêmicos ou não no controle da ferrugem do feijoeiro, como carboxin ou oxycarboxin (ZAMBOLIM \& CHAVES, 1978), bitertanol (SANTINI, 1989), diniconazole (MANÇO, 1988), etiltrianol (GOULART, 1990; SANTINI, 1989), chlorothalonil (SARTORATO et al., 1983; CASTRO et al., 1989), mancozeb (SARTORATO et a l., 1983) e tebuconazole (OLIVEIRA et al., 1992). Estes produtos não apresentam ação curativa para a ferrugem na fase de pústula com liberação de uredosporos. Muitas vezes, quando o agricultor percebe a ferrugem na sua cultura, torna-se muito difícil controlá-la com defensivos de ação preventiva, em condições favoráveis ao desenvolvimento da doença. Neste caso, somente um produto de ação curativa seria capaz de interromper o ciclo da doença, reduzindo drasticamente o potencial de inóculo ou até errdicando o patógeno.

Em observações preliminares (ITO et al., 1991), foi constatada a ação curativa do inseticida cartap sobre a ferrugem do feijoeiro e assim, neste trabalho, procurou-se avaliar a ação preventiva e curativa do inseticida cartap sobre a ferrugem do feijoeiro, em condições de laboratório e campo. 


\section{REVISÃO DE LITERATURA}

\subsection{A Ferrugem do Feijoeiro}

o Brasil é o maior produtor mundial de feijão,

sendo também seu maior consumidor. O Estado de são Paulo é o segundo produtor nacional, porém com produtividade média de 878 $\mathrm{kg} / \mathrm{ha}$, muito aquém do potencial produtivo do feijoeiro (ANUÁRIO ESTATÍSTICO DO BRASIL, 1991). Através do uso da irrigação, algumas regiōes do Estado de são Paulo têm alcançado uma produtividade média de $1.800 \mathrm{~kg} / \mathrm{ha}$ (FANCELLI, 1988).

varios fatores contribuem para a baixa produtividade brasileira do feijoeiro. Dentre estes fatores destacam-se as doenças causadas por fungos, bactérias e vírus, podendo em alguns casos ser limitante à cultura (KIMATI, 1980; CASTRO, 1988). Dentre as doenças foliares causadas por fungos, a ferrugem é uma das principais, podendo causar perdas na produção de até 100\% (NASSER et al., 1977). Ela também é 
considerada uma das principais doenças da cultura do feijão vagem (FRENHANI et al., 1971; YAMAMOTO et al., 1971; CASTELLANE et al., 1988; TANAKA et al., 1991).

A ferrugem do feijoeiro é causada pelo fungo Uromyces appendiculatus e foi relatada pela primeira vez na Alemanha, em 1795, por Person', citado por ZAUMEYER \& THOMAS (1957). O patógeno está amplamente disseminado nas regiões produtoras de feijão, com intensidade variável, causando desfolha prematura em culturas severamente afetadas. Os prejuízos são maiores quando a doença ocorre antes ou durante a floração (SARTORATO et al., 1983).

As condições favoráveis para o desenvolvimento da ferrugem são temperatura baixa, variando de 17 a $27^{\circ} \mathrm{C}$ e umidade relativa superior a 95\%, por um período diário de 10 a 18 horas (KIMATI, 1980; SARTORATO et al., 1983 ; CASTELLANE et al., 1988).

- fungo U. appendiculatus é macrociclico, apresentando todos os tipos de esporos (picniosporos, eciosporos, uredosporos, teliosporos e basidiosporos), e também é autóico, pois completa o seu ciclo num mesmo hospedeiro (GROTH \& MOGEM, 1978 ; KIMATI, 1980; SCOTT \& CHAKRAVORTY, 1982).

1 PERSON, C.H. Observations mycologicae. In: Usteri, P. Annalen der Botanik, Leipzig, 3(15): 1-43, 1975. 
A ferrugem do feijoeiro ocorre em vagens, ramos, peciolos e mais comumente nas folhas. As infecçōes iniciais ocorrem por meio da superfície superior ou inferior das folhas, porém normalmente aparecem na superficie inferior, como manchas puntiformes, esbranquiçadas, que em condições favoráveis aparecem cinco dias após a inoculação. Os tubos germinativos penetram pelo estômato e se desenvolvem nas cavidades estomatais e espaços intercelulares. Os soros vão aumentando gradualmente em tamanho e em oito a dez dias rompem as suas epidermes, expondo os uredosporos. Estes soros continuam a crescer por muitos dias. Em cultivares altamente suscetiveis, os soros podem ter de 1 a $2 \mathrm{~mm}$ de diâmetro (ZAUMEYER \& THOMAS, 1957; KIMATI, 1980; VIEIRA, 1983). No final do ciclo das plantas, quando as pústulas tornam-se velhas, aparecem os teliosporos. Nas regiōes tropicais os teliosporos e os eciosporos raramente são encontrados na natureza (ZAUMEYER \& THOMAS, 1957). O tipo de esporo mais comum produzido pela ferrugem é o uredosporo, também denominado de esporo de verão (SCHWARTZ \& GALVEZ, 1980).

A principal forma de disseminação da ferrugem, é por meio dos uredosporos. Eles são disseminados por insetos, animais, implementos agrícolas e o próprio homem. \̀ longa distância, o principal agente de disseminação é o vento (ZAUMEYER \& THOMAS, 1957; KIMATI, 1980). Segundo KIMATI (1980), quando existem duas épocas de plantio, o potencial de inóculo 
é mantido, sendo os uredosporos transportados pelo vento, preservando a sobrevivência de $U$. appendiculatus em hospedeiros suscetíveis. o cultivo intensivo do feijoeiro em algumas regiōes do Estado de São Paulo, com três plantios anuais (CASTRO, 1988; FANCELLI, 1988), tem contribuído nos últimos anos para a manutenção de níveis altos do potencial de inóculo dos patógenos nesta leguminosa.

Os uredosporos são produzidos em grande quantidade no soro, nas superficies superior e inferior da folna e podem germinar tão logo amadureçam. Em condições favoráveis de temperatura e umidade produzem outra geração, em cerca de 10 a 15 dias. A rapidez na sua multiplicação resulta em muitas gerações num único ciclo da cultura (ZAUMEYER \& THOMAS, 1957).

\subsection{Controle da Ferrugem do Feijoeiro}

o uso de cultivares resistentes é o método ideal para o controle da ferrugem do feijoeiro, porém o trabalho de melhoramento torna-se difícil devido ao grande número de raças fisiológicas de $U$. appendiculatus (ZAUMEYER \& THOMAS, 1957; KIMATI, 1980). Assim, as variedades comerciais dificilmente apresentam resistência a todas as raças fisiológicas conhecidas (KIMATI, 1980). Um cultivar híbrido, com resistência a muitas raças, pode tornar-se suscetível a uma nova raça desconhecida, com pouco tempo de cultivo (ZAUMEYER \& THOMAS, 1957). 
Para o controle da ferrugem do feijoeiro são recomendados, além do uso de variedades resistentes, outras práticas, como rotação de culturas, eliminação de restos culturais, escolha de época de plantio, integrados à aplicação de fungicidas (ZAUMEYER \& THOMAS, 1957; KIMATI, 1980; SARTORATO et al., 1983).

Desde a sua descoberta na Alemanha, em 1795, a ferrugem tem sido relatada em inúmeros locais do mundo, acusando até perdas totais na lavoura, e constituindo-se numa das principais doenças do feijoeiro (ZAUMEYER \& THOMAS, 1957). Pela dificuldade de seu controle, em alguns casos, somente a aplicação de um fungicida pode evitar a perda da cultura. No decorrer do tempo, observa-se que a ferrugem sempre foi uma doença preocupante, induzindo a pesquisa, na área de controle químico, à deteç̧ão de novos produtos para o seu controle.

Fungicidas de primeira geração, ou compostos inorgânicos, já foram empregados no controle da ferrugem do feijoeiro. Em 1936, no sul da África, Wager ${ }^{2}$, citado por ZAUMEYER \& THOMAS (1957), constatou que a ferrugem era controlada através de pulverizações semanais com calda bordaleza, especialmente logo após as chuvas.

2 WAGER, V.A. Bacterial wild and blight of french beans. Union So. Africa Dept. and Forestry, Plant Indus. Ser. 14. Sci. Bul. 149; 19p. ilust., 1936. 
A calda sulfocálcica foi bastante utilizada como mostram alguns trabalhos. YARWOOD (1940), verificou que vapores de enxofre controlaram as infecções após o aparecimento dos sintomas da ferrugem, porém sem fitotoxicidade aparente nas plantas. A partir desta data, este autor realizou outros trabalhos, demonstrando a eficiência da calda sulfocálcica sobre a ferrugem do feijoeiro (YARWOOD, 1943; YARWOOD, 1947; YARWOOD, 1948).

MILBRATH (1944) relata que grande número de teliosporos ficavam aderidos às estacas utilizadas na cultura de feijão vagem, sendo que a cultura seguinte, com o emprego destas estacas contaminadas, apresentavam invariavelmente maior infeç̧ão precoce do que nos campos onde eram utilizadas estacas novas. Nos trabalhos conduzidos em casa de vegetação MILBRATH (1944) mostrou que o emprego de estacas contaminadas deu origem a numerosas pústulas picniais no feijoeiro, em três a quatro semanas, enquanto que plantas não estaqueadas permaneceram-se sadias. Este autor mergulhou as estacas contaminadas na mistura cálcio-enxofre ou sulfato de cobre e conseguiu prevenir a infecção. Verificou também que a pulverização com enxofre iniciada antes da formação dos eciosporos e em intervalos de sete dias, reduziu a infecção do feijoeiro.

ZAUMEYER \& GOLDSWORTHY (1945) observaram que enxofre, nas formas de pó e liquido, nabam e naftoquinona clorado, foram altamente eficientes no controle de infecções da ferrugem, em casa de vegetação, erradicando o fungo 24 horas 
após a infeç̧ão, enquanto que compostos de cobre não foram tão eficientes. No campo, o controle foi obtido com o polvilhamento de enxofre na dosagem de 20-25 libras/ha, antes e imediatamente após as primeiras infeç̧ões primárias. Em outro trabalho (ZAUMEYER, 1946), o polvilhamento de enxofre em plantas de feijão, cultivares Pinto e Great Northern, controlou a ferrugem em culturas desenvolvidas nos Estados do Colorado, Wyoming e Montana. O enxofre foi aplicado na dosagem de 20 a 25 libras/ha. O autor observou que em wyoming, campos com duas pulverizações aumentaram a produtividade em relação à testemunha, sendo de 1.600-1.800 libras de sementes/ha e 800 a 1.000 libras/ha, respectivamente. Em Montana, o melhor campo, pulverizado duas vezes, produziu 2.369 libras/ha e o pior, sem pulverização, produziu $380 \mathrm{libras/ha.}$

Com o desenvolvimento dos fungicidas orgânicos, ou de segunda geração, a ferrugem do feijoeiro também passou a ser controlada por este grupo de defensivos. Foi comprovada a ação do zineb, que apresentou melhores resultados, quando comparado com enxofre e oxicloreto de cobre, conforme Casarini ${ }^{3}$, citado por FRENHANI et al. (1971). No ano seguinte, vliet ${ }^{4}$ citado por FRENHANI et al., 1971, comprovou a eficiência do zineb, quando pulverizado na concentração de $0,35 \%$

3 CASARINI, B. Prove li lotta contro la ruggine del fagiolo (Uromyces appendiculatus (Pers.) LK.). Annali della Sperimentazione Agraria, Roma, III(4): 1172-80, 1954 .

4 VLIET, M.D. De Bestrijiding van de bonenroest (Abstract). Tijdscher over Plantenziekten, 61: 26, 1955. 
ISSA \& ARRUDA (1964) realizaram quatro experimentos para verificar o controle da ferrugem e da antracnose do feijoeiro e observaram que apenas a pulverização com maneb proporcionou um aumento na produtividade da cultura, em relação a outros fungicidas testados.

Ao avaliarem o efeito do volume de calda, pressão de pulverização e disposição de bico na cobertura foliar e controle da ferrugem do feijão vagem, TOMPKINS et al. (1983) empregaram o fungicida chlorothalonil (2,5 kg i.a./ha). observaram que os tratamentos avaliados não apresentaram efeito significativo no controle da ferrugem, mas que as parcelas pulverizadas regularmente com chlorothalonil proporcionaram controle significativo. Quanto à produtividade, embora nenhum dos tratamentos tenha proporcionado diferença, as parcelas pulverizadas produziram mais que aquelas não pulverizadas.

A descoberta dos fungicidas de terceira geração, ou sistêmicos, teve início na década de 1960. VON SCHMELING \& KULKA (1966) testaram dois compostos derivados de 1,4-oxathiin, através do tratamento de sementes de feijão e cevada, e constataram a ação fungicida sistêmica destes derivados, sobre Uromyces appendiculatus e Ustilago nuda, sem causar danos aos hospedeiros.

Sementes de feijão foram tratadas com os dois compostos a $0,25 \%$ por peso de semente e semeadas em vaso, em casa de vegetação. Realizaram inoculações em intervalos de uma 
a duas semanas, com uredosporos de $U$. appendiculatus. Os dois compostos controlaram efetivamente $\circ$ desenvolvimento dos sintomas da ferrugem sobre as folhas primárias, quando inoculadas sete dias após plantio. O carboxin proporcionou controle de $99 \%$ e o oxycarboxin, $100 \%$.

No tratamento com intervalo de duas semanas, entre plantio e inoculação, o oxycarboxin proporcionou $99 \%$ de controle nas folhas primárias e 96\% nas trifoliadas, enquanto que o carboxin não apresentou controle. Os dois compostos pareciam ser translocados através do xilema até o sítio do patógeno e esses derivados de 1,4-oxathiin constituíam-se numa nova classe de fungicidas sistêmicos (VON SCHMELING \& KULKA, $1966)$.

No ano seguinte, VAUGAN \& SIEMER (1967) avaliaram os mesmos derivados de 1,4-oxathiin, através do tratamento de sementes de feijão, à concentração de $1 \mathrm{~g} / 100 \mathrm{~g}$ de sementes. os dois compostos foram efetivos ao $U$. appendiculatus, sendo o derivado F-461 (oxycarboxin) melhor que o D-735 (carboxin). O mesmo controle relativo foi observado sobre a primeira, segunda e terceira folhas trifoliadas, quando foram efetuadas pulverizações a $400 \mathrm{ppm}$, aos dois, quatro, seis e oito dias após a inoculação, sendo oxycarboxin mais efetivo que carboxin. Os autores observaram também controle foliar preventivo em folhas primárias e primeira, segunda e terceira folhas trifoliadas, por ambos compostos, com resultados semelhantes. 
BATES \& TWEEDY (1971) trataram plantas sadias e infectadas e o fungo $U$. appendiculatus, com várias concentraçōes de oxycarboxin. Realizaram estudos de germinação e respiração dos uredosporos, utilizando 10,50 e $100 \mu \mathrm{g} / \mathrm{ml}$ de oxycarboxin, com amostras tomadas em intervalos de 1 hora. observaram que o fungicida retardou a germinação dos esporos, porém sem causar sua inibição. A extensão do tubo germinativo e a taxa de respiração foram altamente inibidos, contudo oxycarboxin não apresentou efeito sobre o crescimento e a taxa de respiração da planta. Foi observado que a translocação de oxycarboxin das raízes às folhas ocorreu em 1 hora e que houve um rápido aumento de material, marcado $\operatorname{com} \mathrm{C}^{\mathbf{1 4}}$, ao redor do sitio de infecção. Constataram também que após um periodo de incubação de 72 horas, a concentração do produto na pústula foi 50 vezes maior que em partes não infectadas da planta.

No Brasil, após a descoberta dos derivados de 1,4-oxathiin, carboxin e oxycarboxin, muitas pesquisas foram efetuadas para comprovar a eficiência destes compostos, sobre a ferrugem do feijoeiro. FRENHANI et al. (1971) realizaram dois experimentos com este objetivo, em Campinas, utilizando os cultivares Rosinha e Bico de ouro. No primeiro, estudaram o produto, em tratamento de sementes, nas dosagens de 1,25; 2,5 e $5,0 \mathrm{~g} / \mathrm{kg}$ de sementes e em pulverização foliar, na dosagem de 1.815; 2.720 e $3.400 \mathrm{~g} / \mathrm{ha}$. No segundo experimento, os tratamentos foram os mesmos, porém comparados com o fungicida 
maneb. os resultados mostraram que oxycarboxin, em pulverização, proporcionou excelentes resultados, controlando a doença na dosagem de $1.815 \mathrm{~g} / \mathrm{ha}$, em duas aplicações, aos 20 e 40 dias após o plantio. Já a eficiência do fungicida, quando aplicado às sementes, não foi a mesma, proporcionando uma relativa proteção, somente durante as primeiras fases de seu ciclo.

Neste mesmo ano, YAMAMOTO et al. (1971) avaliaram o oxycarboxin, no controle da ferrugem do feijão vagem. Realizaram experimentos em dois locais. Em Biritiba Mirim, testaram os produtos: maneb a $0,3 \%$, propineb a $0,25 \%$, enxofre a $0,2 \%$ e $0,3 \%$, oxycarboxin a $0,2 \%$ e $0,3 \%$, zineb $42 \%+$ enxofre $20 \%$ + oxicloreto de cobre $10 \%$ e enxofre micronizado a $0,3 \%$. No ensaio realizado em Atibaia, avaliaram os produtos: maneb a $0,3 \% ;$ propineb a $0,25 \%$, maneb a $0,15 \%$ + hexaclorofeno a $0,15 \%$, oxycarboxin a $0,2 \%$ e $0,3 \%$, carboxin a $0,25 \%+$ oxycarboxin e enxofre micronizado a $0,3 \%$. Os resultados obtidos mostraram que o fungicida oxycarboxin e a mistura carboxin + oxycarboxin foram altamente eficientes no controle da ferrugem do feijão vagem. Os fungicidas maneb e propineb foram intermediários, proporcionando proteção regular. A melhor produtividade foi apresentada por oxycarboxin e a mistura de oxycarboxin + carboxin.

Em trabalho comparando o oxycarboxin com pyracarbolid, carbendazin e enxofre, sobre a ferrugem do feijão 
vagem, a associação pyracarbolid + carbendazin proporcionou maior eficiência no controle (CAMPACCI et al., 1975). quanto à produtividade, oxycarboxin e a associação pyracarbolid + carbendazin, foram os melhores tratamentos.

PAIVA et al. (1976) compararam o oxycarboxin com pyracarbolid e maneb, no controle da ferrugem do feijoeiro, sobre o cultivar Roxinho. Constataram que todos os fungicidas controlaram a doença, sendo que oxycarboxin e maneb propocionaram as maiores produções.

NASSER et al. (1977) estudaram o efeito do número de aplicações de oxycarboxin sobre a ferrugem, em diferentes estádios de desenvolvimento do feijoeiro. Oxycarboxin foi aplicado em intervalos de 10 dias, sendo 2, 4, 6 e 7 o número de aplicações, nas épocas de floração, enchimento de vagem e colheita. Os cultivares avaliados foram o Porto Alegre, Vagem Roxa e Rico 23. Não obtiveram diferenças, num dos ensaios. Em outro, houve diferença apenas entre a testemunha e as parcelas tratadas, para todos os parâmetros estudados, nas épocas de floração e enchimento de vagem. Na época da colheita, houve diferenças significativas para número de vagens, peso seco da palhada e rendimento. Quanto ao número de aplicações, não houve diferença, assim como o peso de sementes. As plantas pulverizadas apresentaram menor número de vagens.

Fungicidas sistêmicos, sozinhos ou em mistura 
com protetores, foram avaliados quanto ao controle da ferrugem do feijoeiro, com o cultivar Rico 23 (ROLIM et al., 1981a). Os fungicidas foram: mancozeb $82 \%$, chlorothalonil $25 \%+$ oxicloreto de cobre 30\%, oxycarboxin 19\%, mancozeb $82 \%$ + captafol 39\%, oxycarboxin 19\% + captafol 39\%, triforine 39\%, triforine $19 \%+$ captafol $39 \%$ e triforine $19 \%+$ dithianon $75 \%$. Oxycarboxin $(2,0$ 1/ha) foi o melhor tratamento, seguido de triforine $(1,51 /$ ha $)$. Mancozeb comportou-se como intermediário e as misturas chlorothalonil com oxicloreto de cobre, e tiofanato metilico com chlorothalonil foram inferiores, embora superiores à testemunha. A maior produção foi obtida por oxycarboxin. Quanto ao peso de grãos, não houve diferença entre os tratamentos. TANAKA \& JUNQUEIRA NETO (1982) avaliaram os fungicidas sistêmicos tiofanato metílico, benomyl, thiabendazol, pyracarbolid e carboxin, sobre as doenças do feijoeiro e observaram que tiofanato metílico, na dosagem de 50 g/100 litros de água, foi o mais eficiente no aumento da produção de grãos e no controle das doenças antracnose, mancha angular, ferrugem e oídio.

MANÇO (1988) comparou o efeito do fungicida diniconazole, em várias dosagens, com triadimefon e oxycarboxin, sobre as ferrugens do cafeeiro, feijoeiro, figueira, goiabeira, pessegueiro e trigo. Constatou que diniconazole proporcionou bom controle das doenças, nas dosagens de 125 e $250 \mathrm{~g}$ i.a./ha, sendo que, para a ferrugem do 
feijoeiro, a $125 \mathrm{~g}$ foi semelhante a triadimefon e oxycarboxin, e a $250 \mathrm{~g} \mathrm{i.a./ha} \mathrm{foi} \mathrm{superior} \mathrm{a} \mathrm{ambos.}$

No experimento visando avaliar o efeito de fungicidas sobre as doenças do feijoeiro, CASTRO et al. (1989) testaram os fungicidas benomyl, mancozeb, tiofanato metílico, captafol e chlorothalonil, com intervalo de 10 dias, a partir de 1 mês de idade, nos cultivares Cerro Azul, Carioca Comum e Carioca 80. A ferrugem ocorreu apenas em folhas do cultivar Cerro Azul, sendo melhor controlada por mancozeb e chlorothalonil. Observaram que todos os fungicidas reduziram a incidência de doenças, com aumento da produção do cultivar Cerro Azul. Para 'Carioca Comum', destacaram-se o captafol e chlorothalonil e para 'Carioca 80', somente o chlorothalonil. com o objetivo de avaliar a eficiência de diferentes fungicidas no controle de doenças foliares do feijoeiro, GOULART (1990) utilizou os fungicidas etiltrianol $(0,125 \mathrm{l} ; 0,188$ e $0,250 \mathrm{l} \mathrm{i} \cdot \mathrm{a} \cdot / \mathrm{ha})$, tolyfluanid $(0,750 \mathrm{~kg}$ e 1,0 $\mathrm{kg} \mathrm{i.a./ha),} \mathrm{anizaline}(1,875 \mathrm{~kg}$ e $1,920 \mathrm{~kg} \mathrm{i.a./ha)} \mathrm{e}$ bitertanol $(0,125 \mathrm{~kg} \mathrm{i.a./ha).} \mathrm{As} \mathrm{aplicações} \mathrm{foram} \mathrm{aos} \mathrm{28,} 42$ e 62 dias após a semeadura. O trabalho foi realizado em Janaúba-MG, com o cultivar Carioca 80. O autor concluiu que a aplicação de fungicidas promoveu um bom controle da mancha angular, antracnose, ferrugem e mancha de Alternaria, com aumento do rendimento e manutenção do "stand". Os fungicidas etiltrianol $(0,188$ e $0,2501 \mathrm{i} . \mathrm{a} \cdot / \mathrm{ha})$ e bitertanol $(0,125 \mathrm{~kg}$ 
i.a./ha) foram os melhores para o controle da ferrugem.

$$
\text { Com o mesmo objetivo, CASTRO et al. }
$$

avaliaram, em Capão Bonito - SP, os fungicidas: benomyl, mancozeb, tiofanato metílico, captafol, chlorothalonil, acetato de trifenil estanho, carbendazin, thiabendazol, oxicloreto de cobre, sulfato de cobre e hidróxido de trifenil estanho. Os ensaios foram conduzidos nas safras da seca e das águas de 1985 e 1986, com os cultivares Carioca e Carioca 80, efetuando-se 6 pulverizações, com intervalo de 10 dias, iniciando-se aos 30 dias após a emergência. A ferrugem ocorreu apenas nas safras da seca/86 e águas/86, com baixa severidade. Na safra da seca/86, não houve diferença entre os tratamentos, para o cultivar Carioca, e para o cultivar Carioca 80 , todos os fungicidas foram iguais, diferindo da testemunha. Na safra das águas/86, no cultivar Carioca, todos os tratamentos foram iguais, diferindo da testemunha, exceto oxicloreto de cobre, com comportamento intermediário. No cultivar Carioca 80 , 0 melhor controle foi proporcionado por chlorothalonil, seguido de acetato de trifenil estanho. Quanto à produtividade, constataram diferenças apenas em duas safras; seca/85 e águas/86, nos dois cultivares. Na safra da seca/85 no cultivar Carioca, os fungicidas captafol, chlorothalonil, acetato de trifenil estanho e carbendazin foram os melhores. Para 'Carioca $80^{\prime}$, os fungicidas mancozeb, chlorothalonil, acetato de 
trifenil estanho, oxicloreto de cobre e sulfato de cobre deram os melhores resultados. Na safra das águas/86, no cultivar Carioca, os melhores fungicidas foram o acetato de trifenil estanho e hidróxido de trifenil estanho e no cultivar carioca 80 foi o hidróxido de trifenil estanho.

Recentemente, OLIVEIRA et al. (1992) avaliaram a eficiência de nove fungicidas no controle de doenças da parte aérea e qualidade das sementes do feijoeiro, em Capão Bonito-sP e Itapeva-SP. As pulverizações foram iniciadas aos 30 dias após a emergência, com intervalos de 15 dias, totalizando três aplicações. Os fungicidas em $\mathrm{kg}$ i.a./ha foram: tiofanato metílico + chlorothalonil $(0,98)$, chlorothalonil $(1,0)$, mancozeb $\mathrm{BR}(2,0)$, mancozeb $\mathrm{BR}+\operatorname{carbendazin}(2,0+2,5)$, carbendazim $(0,25)$, mancozeb $\operatorname{DF}(1,75)$, acetato de trifenil estanho $(0,20)$, bitertanol $(0,24)$ e tebuconazole $(0,18)$. A ferrugem ocorreu apenas em Capão Bonito, com baixa incidência. Somente tebuconazole e bitertanol foram superiores à testemunha. Quanto à produtividade, houve diferença apenas em Capão Bonito, sendo que o melhor fungicida foi o acetato de trifenil estanho, seguido de chlorothalonil, tiofanato metílico + chloro-thalonil, bitertanol e tebuconazole.

BALARDIN (1993) avaliou a eficiência de tiofanato metílico, chlorothalonil e tiofanato metílico + chlorothalonil no controle da ferrugem e oídio do feijoeiro. Utilizou os cultivares Carioca e Goiano Precoce, efetuando as 
pulverizações nos estádios $V_{4}$ (terceira folha trifoliada), $R_{5}$ (pré-floração) e $R_{8}$ (enchimento de vagens). O autor observou que todos os fungicidas apresentaram ganhos no rendimento, porém quanto à redução na severidade da ferrugem, os fungicidas não diferiram entre si. Apresentaram redução acentuada na severidde de oidio, sendo que os fungicidas protetores foram mais eficientes.

o uso de fungicidas aliados aos diferentes métodos de controle de doenças tem proporcionado ganhos na produção (TANAKA \& JUNQUEIRA NETO, 1982; CASTRO et al., 1989; GOULART, 1990; BARROS \& CASTRO; 1991; CASTRO et al., 1991; OLIVEIRA et al., 1992; BALARDIN, 1993). Os principais produtos químicos empregados no controle da ferrugem do feijoeiro, desde os compostos inorgânicos, protetores orgânicos e fungicidas sistêmicos, com os recentes triazóis, apresentam basicamente ação preventiva e pouca ação curativa sobre $U$. appendiculatus. Não se conhece ainda, por meio da literatura consultada, um produto que atue sobre os uredosporos após a sua maturação.

Alguns inseticidas já foram relatados apresentando efeitos sobre fungos, em aplicações no solo ou tratamento de sementes. RICHARDSON (1959) observou que aplicações de aldrin e endrin, no solo, reduziram a murcha do tomateiro, causada por Fusarium oxysporum f. lycopersici e que aldrin, dieldrin e endrin diminuíram a incidência foliar de Alternaria solani. O inseticida BHC, ou hexaclorociclo-benzeno, 
empregado no tratamento de sementes tem mostrado eficiência no controle de Tilletia caries e T. controversa (TYLER \& JENSEN, 1963: PURDY, 1965). Assim como estes inseticidas, cartap tem mostrado efeito fungicida sobre $U$. appendiculatus (ITO et al., $1991)$ 


\section{3. material E metodos}

\subsection{Experimentos de Laboratório}

3.1.1. Ação fungicida do cartap sobre uredosporos de $U$. appendiculatus

o inseticida cartap, na concentração de 0,3 g i.a./l foi aplicado em folhas de feijoeiro, cultivar Rosinha G2, apresentando pústulas produzindo uredosporos de $U$. appendiculatus. Após 24 horas, os uredosporos que eram marrons tornaram-se brancos.

As suspensões de esporos para este teste foram preparadas com os uredosporos brancos e uredosporos marrons, separadamente, em solução de Tween 80 a 0,02\% (MENDES, 1985). A concentração de uredosporos na suspensão foi de $2.10^{4}$ uredosporos/ml. Cada suspensão foi pulverizada por meio de um atomizador de vilbiss sobre a superfície de 10 lâminas cobertas com agar-água. As lâminas foram colocadas em placas de Petri contendo dois discos de papel de filtro $\left(80,0 \mathrm{~g} / \mathrm{m}^{2}\right)$ previamente umedecidos com água destilada e esterilizada e incubadas à 
temperatura de $21^{\circ} \mathrm{C}\left( \pm 1^{\circ} \mathrm{C}\right)$, no escuro, durante 24 horas. Após este período, 200 uredosporos de cada lâmina foram observados sob microscópio estereoscópio, no aumento de 50 vezes, para a avaliação da germinação.

\subsubsection{Ação fungicida do cartap sobre uredosporos de $U$. appendiculatus, "in vivon}

As suspensões de esporos, preparadas como no item 3.1.1., foram aplicadas por meio de um atomizador de Vilbiss, nas superficies superior $e$ inferior das folhas primárias, bem expandidas, de plântulas de feijoeiro, com 5 dias de idade, do cultivar Rosinha G-2, segundo MENDES (1985). Foram utilizados quatro vasos, cada um contendo duas plantas, para cada tipo de inóculo. Após a inoculação, as plântulas foram mantidas em câmara úmida, no escuro, à temperatura de $21^{\circ} \mathrm{C}\left( \pm 1^{\circ} \mathrm{C}\right)$, durante 48 horas. Com a retirada da câmara úmida as plântulas permaneceram num ambiente, sob luz do dia, fotoperíodo de 12 horas, a $21^{\circ} \mathrm{C}\left( \pm 1^{\circ} \mathrm{C}\right)$. A avaliação da infecção foi efetuada 12 dias após a inoculação.

\subsubsection{Ação do cartap sobre "flecks" e uredosporos de $U$. appendiculatus}

Folhas primárias de plântulas de feijoeiro do cultivar Rosinha G-2, com cinco dias de idade e folhas 
trifoliadas com quatro dias foram inoculadas com $U$. appendiculatus. O inóculo foi preparado com uredosporos normais coletados de folhas de plantas do cultivar Rosinha G-2 utilizadas para a multiplicação do fungo. Folhas com pústulas contendo uredosporos foram agitadas sobre uma folna de papel, segundo MENDES (1985), coletando-se assim somente os uredosporos maduros. O inóculo foi preparado como no item 3.1.1, com uredosporos normais. A inoculação foi efetuada por meio da pulverização das duas faces das folhas, com um atomizador de vilbiss, mantendo-se as plantas em câmara úmida e regime de luz, como no item 3.1 .2 .

o inseticida cartap foi utilizado na concentração de $0,3 \mathrm{~g}$ i.a./l e pulverizado quando as folhas trifoliadas apresentavam sintomas na fase de "fleck" e presença de uredosporos normais nas folhas primárias. Para cada teste, foram utilizados cinco vasos com duas plantas por vaso. A avaliacão foi efetuada observando-se a formação de uredosporos inviáveis (brancos) no tratamento com "fleck", ou a inviabilização dos uredosporos no tratamento com uredosporos normais.

\subsubsection{Ação preventiva do cartap sobre U. appendiculatus}

Plântulas de feijoeiro do cultivar Rosinha G-2 com as folhas primárias bem expandidas, com a idade de cinco 
dias foram pulverizadas com cartap a $0,75 \mathrm{~g} \mathrm{i.a./ha,} \mathrm{a} \mathrm{cada} 24$ horas, obtendo-se tratamentos com 1, 2, 3, 4, 5 e 6 dias após a aplicação do produto e o tratamento testemunha. Em seguida foi efetuada a inoculação conforme descrita no item 3.1.3. o delineamento experimental foi o inteiramente casualizado, com quatro repetições, sendo cada repetição representada por um vaso com duas plantas.

A avaliação do efeito do cartap sobre o fungo foi efetuada 12 dias após a inoculação, por meio da contagem do número de pústulas com esporos normais, quando as pústulas das folhas do tratamento testemunha apresentavam-se esporuladas.

Os dados foram submetidos à análise de variância, sendo transformados em $\sqrt{x}$ e as médias comparadas pelo teste de Tukey a 5\% de probabilidade.

\subsubsection{Ação curativa do cartap sobre $U$. appendiculatus}

Folhas primárias de plântulas de feijoeiro do cultivar Rosinha G-2 foram inoculadas conforme descrito no item 3.1 .3 .

Cada tratamento foi constituído por quatro vasos com duas plantas e pulverizado com cartap na concentração de $0,75 \mathrm{~g}$ i.a./1 a cada 24 horas, obtendo-se plântulas com tratamento de $1,2,3,4$ e 5 dias após a inoculação.

A testemunha foi constituida por quatro vasos 
com duas plantas cada.

o delineamento experimental foi o inteiramente casualizado, com quatro repetições, sendo cada repetição representada por um vaso com duas plantas.

A avaliação visual da esporulação foi efetuada 12 dias após a inoculação, quando as pústulas das folhas do tratamento testemunha apresentavam-se esporuladas. Utilizou-se uma escala de notas de 1 a 6 , sendo $1=0 \%$ de controle; $2=1$ a $10 \% ; 3=11$ a $25 \% ; 4=26$ a $55 \% ; 5=56$ a $80 \%$ e $6=>80 \%$ de controle. A porcentagem de controle foi em relação à testemunha, sendo considerada a quantidade de pústulas com uredosporos brancos.

\subsubsection{Ação erradicante do cartap sobre U. appendiculatus, em associação com fungicidas}

Plântulas de feijoeiro do cultivar Rosinha G2, apresentando as folhas primárias bem expandidas, com idade de cinco dias, foram inoculadas com $U$. appendiculatus, conforme descrito em 3.1.3. Doze dias após a inoculação, quando as folhas primárias já apresentavam pústulas com uredosporos, elas foram pulverizadas com os seguintes produtos em $\mathrm{g}$ i.a./ha: cartap - 750, triforine - 285, enxofre - 1.560, tiofanato metílico + chlorothalonil - 350 + 875, oxycarboxin - 600, 
chlorothalonil - 1.250, mancozeb - 1.600, hidróxido de trifenil estanho - 200, fertamin-M - 51 (p.c.), cartap + triforine $750+285$, cartap + enxofre $-750+1.560$, cartap + triofanato metilico + chlorothalonil - $750+350+875$, cartap + oxycarboxin - 750 + 600, cartap + chlorothalonil - $750+1.200$, cartap + mancozeb $-750+1.600$, cartap + hidróxido de trifenil estanho $-750+200$, cartap + fertanin-M - $750+51$ (p.c.) e testemunha pulverizada com água. A pulverização foi efetuada na proporção de 5001 de calda/ha.

o delineamento experimental foi de blocos ao acaso com quatro repetições, sendo cada uma representada por um vaso contendo duas plantas.

A avaliação visual do controle foi efetuada aos 7 e 14 dias após a aplicação dos produtos, utilizando-se a escala de notas de 1 a 6 , descrita no item 3.1.5.

Os dados foram submetidos à análise de variância, sendo transformados em arc sen $\sqrt{x / 100}$ e as médias foram comparadas pelo teste de Tukey a 5\% de probabilidade.

\subsection{Experimentos de. Campo}

\subsubsection{Efeito fungicida do cartap sobre a ferrugem do feijão vagem}

Foram avaliados os efeitos preventivo e curativo dos produtos químicos cartap, diniconazole e oxycarboxin sobre 
a ferrugem do feijão vagem. Foram também avaliados os efeitos destes produtos sobre a incidência da ferrugem nas vagens, produção de vagens e produtividade.

o experimento foi conduzido em propriedade do município de Jarinu-SP. o cultivar utilizado foi Itatiba II, suscetível a $U$. appendiculatus. A semeadura foi realizada em agosto de 1991 .

Os produtos utilizados e as concentraçōes preparadas em g i.a./100 1 de água foram: cartap - 75,0 (7 e 14 dias); cartap - 100,0; cartap - 125,0; cartap - 75,0; diniconazole - 2,5; oxycarboxin - 75,0 e testemunha pulverizada com água.

Os produtos foram aplicados semanalmente, com exceção de um tratamento com cartap, na concentração de 75,0 g i.a./100 l, que foi aplicado com intervalo de 14 dias, iniciando-se aos 35 dias após a semeadura e totalizando seis pulverizaçōes. As pulverizações foram efetuadas com auxílio de um pulverizador costal, manual, marca Jacto, bico X2, com gasto de 800 litros de calda nas duas primeiras aplicações, e nas demais, 1.000 litros/ha.

o delineamento experimental foi de blocos ao acaso, com quatro repetições, sendo cada parcela constituída de dez covas, com três plantas por cova. Para as avaliações, foram consideradas as cinco covas centrais. O espaçamento foi de 1,0 $\mathrm{x} 0,5 \mathrm{~m}$. 
Para a avaliação dos efeitos preventivo e erradicante, foram marcadas ao acaso nas plantas, 40 folhas trifoliadas sem sintomas visiveis e 40 folhas trifoliadas com 60\% de área foliar com pústulas com uredosporos. O efeito preventivo foi avaliado, utilizando-se uma escala de notas de 1 a 6 , sendo $1=0 \%$ de área foliar com pústulas com uredosporos viáveis; $2=1$ a $10 \% ; 3=11$ a $20 \% ; 4=21$ a $40 \% ; 5=41$ a $70 \%$ e $6=>70 \%$. O efeito erradicante foi avaliado semanalmente, conforme escala descrita no item 3.1 .5 .

Para a avaliação da incidência de ferrugem nas vagens, efetuada na época da quarta colheita, foram consideradas todas as vagens com pústulas.

A produção em número de vagens e a produtividade foram determinadas através de contagens e pesagens cumulativas do número de vagens produzidas, em quatro coheitas obtidas no experimento.

Os dados foram submetidos à análise de variância e as médias comparadas pelo teste de Tukey a 5\% de probabilidade. Somente os dados sobre a ferrugem nas vagens foram transformados em arc sen $\sqrt{x / 100}$.

\subsubsection{Efeito fungicida do cartap sobre a ferrugem do feijoeiro, na safra das águas}

Foi avaliado o efeito dos produtos químicos cartap, chlorothalonil, mancozeb e oxycarboxin sobre a 
ferrugem, peso de 100 sementes e produtividade do feijoeiro. o experimento foi conduzido na Estação

Experimental de Capão Bonito, do Instituto Agronômico de Campinas, utilizando-se o cultivar Aroana 80 , suscetível às raças de $U$. appendiculatus que ocorrem na região. A semeadura foi realizada em novembro de 1991.

Foram empregados os seguintes produtos cujas concentrações em g i.a. foram preparadas para 5001 de cada/ha: 1-cartap - 500; 2-cartap - 750; 3-cartap - 1.000; 4-cartap 500; 5-cartap - 750; 6-cartap - 1.000; 7-chlorothalonil $1.250 ; 8$-mancozeb - 1.600; 9-oxycarboxin - 600 e 10-testemunha pulverizada com água.

Os produtos foram pulverizados, utilizando-se um pulverizador costal manual, marca Jacto, bico X2. Os tratamentos $1,2,3,7$ e 8 foram pulverizados semanalmente, durante quatro semanas e os tratamentos $4,5,6$ e 9 a cada 14 dias, totalizando duas aplicações. A primeira aplicação dos produtos foi realizada quando as plantas estavam com dois meses de idade e as folhas mais velhas apresentavam-se com cerca de 10\% de área foliar com pústulas com uredosporos.

o delineamento experimental foi de blocos ao acaso, com quatro repetições, sendo cada parcela constituída de quatro linhas de $3,0 \mathrm{~m}$ de comprimento, espaçadas de 0,5 $\mathrm{m}$. Foram avaliadas as folhas das plantas das duas linhas centrais. Para a avaliação do efeito dos produtos químicos 
sobre a ferrugem, utilizou-se a escala de notas descrita no item 3.2.1 que foi empregada para a avaliação do efeito preventivo. Foram avaliadas 10 folhas trifoliadas de cada parcela, tomadas ao acaso, uma semana após a quarta aplicação dos produtos.

Os dados foram submetidos à análise de variância e as médias comparadas pelo teste de Tukey a $5 \%$ de probabilidade.

\subsubsection{Efeito fungicida do cartap sobre a ferrugem do feijoeiro, na safra da seca}

Foi avaliado o efeito do inseticida cartap, em comparação com os fungicidas chlorothalonil, enxofre, mancozeb, oxycarboxin e triforine, sobre a ferrugem, peso de 100 sementes e a produtividade do feijoeiro.

o experimento foi conduzido na Estação Experimental de Capão Bonito, do Instituto Agronômico. Foi utilizado o cultivar Aroana 80 , semeado em fevereiro/92.

Foram empregados os seguintes produtos cujas concentrações em g i.a./l foram preparadas para 5001 de calda/ha: cartap - 1.000 (14 dias); cartap - 1.000, cartap 750, enxofre - 1.560, chlorothalonil - 1.250, mancozeb - 1.660, triforine - 285, oxycarboxin - 600 e testemunha pulverizada com água. 
Os produtos foram pulverizados com auxílio de um pulverizador costal, manual, marca Jacto, bico X2.

As pulverizacões foram realizadas semanalmente em todos os tratamentos, exceto no tratamento cartap 1.000 (14 dias) que foi aplicado a cada 14 dias, sendo iniciadas em março de 92, quando as plantas estavam com 34 dias de idade, totalizando quatro aplicações, exceto para o tratamento cartap 1.000 (14 dias) que recebeu apenas duas aplicações.

o delineamento experimental foi o mesmo do item 3.2 .2

O efeito dos produtos químicos sobre a ferrugem foi avaliado utilizando-se a escala de notas de 1 a 6 , descrita no item 3.2.1 para o efeito preventivo, em 10 folhas trifoliadas tomadas ao acaso, por parcela, sempre nas duas linhas centrais.

Os dados foram submetidos à análise de variância e as médias comparadas pelo teste de Tukey a 5\% de probabilidade. 


\section{RESUltados E Discussão}

4.1. Experimentos de Laboratório

4.1.1. Ação fungicida do cartap sobre uredosporos de U. appendiculatus

Os esporos contidos na suspensão preparada com os uredosporos marrons, normais apresentaram germinação de $1,8 \%$, enquanto que os esporos contidos no inóculo preparado com os uredosporos brancos não germinaram. Isto demonstra a ação do inseticida cartap inviabilizando uredosporos normais, ou seja, impedindo a sua germinação.

4.1.2. Ação fungicida do cartap sobre uredosporos de U. appendiculatus, "in vivo"

As folhas inoculadas com o inóculo preparado com uredosporos marrons, normais, típicos apresentaram desenvolvimento normal da ferrugem. Os "flecks" apareceram no quinto dia após a inoculação e a esporulação foi normal e 
ocorreu ao redor do décimo dia após a inoculação. Todavia, não houve nenhum desenvolvimento da ferrugem nas folhas inoculadas com a suspensão preparada com os uredosporos brancos, confirmando a sua inviabilização, induzida pelo inseticida cartap, já observada no teste anterior.

\subsubsection{Ação do cartap sobre "flecks" e uredosporos de U. appendiculatus}

Praticamente todos os uredosporos produzidos nas folhas primárias, após 24 horas da aplicação de cartap, tornaram-se brancos ou inviáveis (Figura 1).

observou-se um desenvolvimento incipiente dos "flecks", nas folhas trifoliadas, que adquiriram uma coloração branca bastante intensa, semelhante a um ponto branco e saliente. Uma pequena porcentagem dos soros obtidos rompeu a epiderme da folha, expondo um número reduzido de uredosporos, totalmente brancos (Figura 2).

Estes resultados indicam que o inseticida cartap apresenta ação erradicante, agindo sobre o desenvol-vimento de U. appendiculatus, desde o estádio de "flecks" até os uredosporos já formados.

A ação do cartap sobre os "flecks" evidencia que o produto penetrou na folha, através da epiderme, atingindo o sítio de infecção de $U$. appendiculatus. 


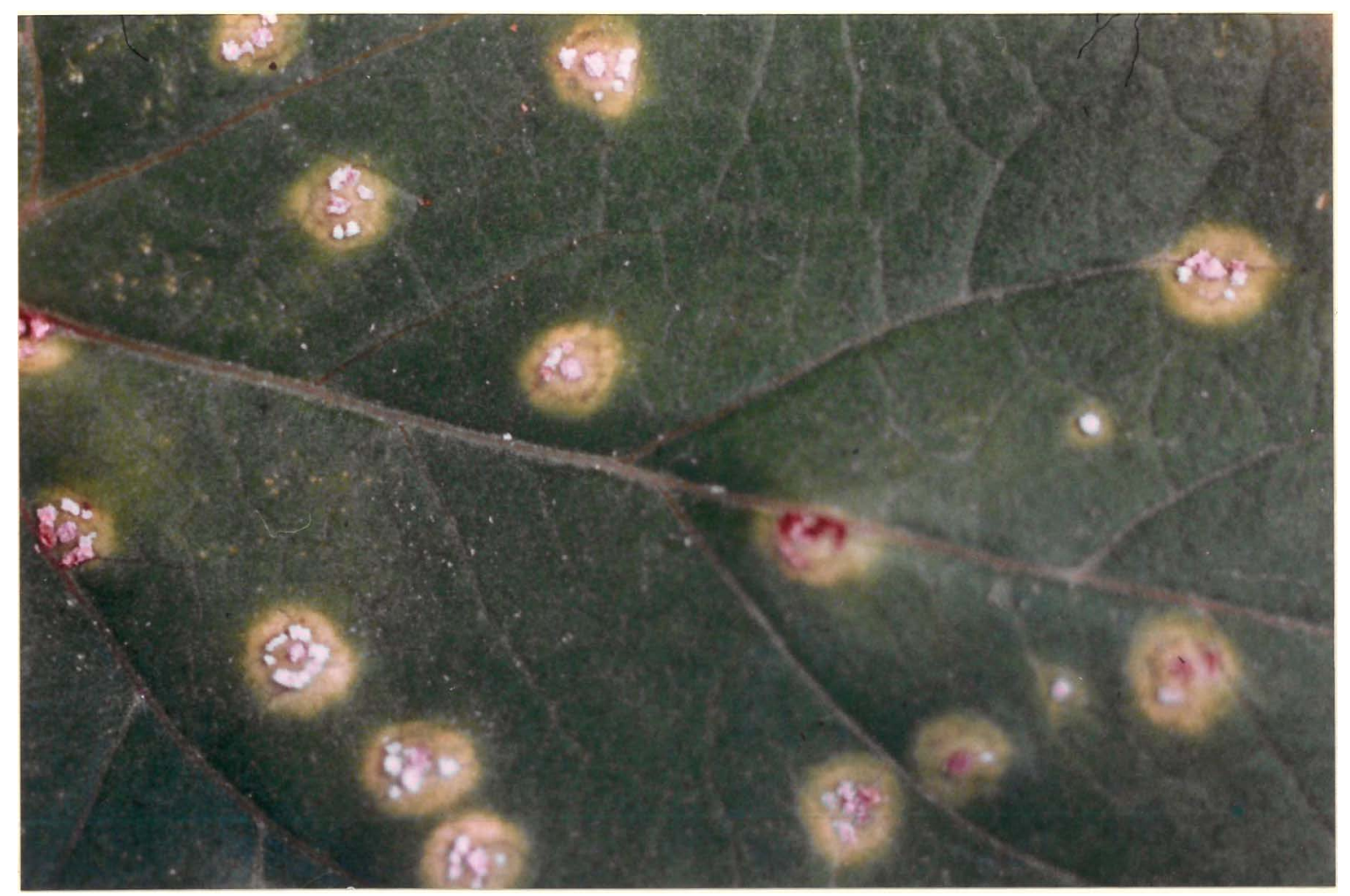

Figura 1. Pústulas de $U$. appendiculatus com uredosporos brancos, inviáveis, sobre folha primária de fei joeiro. 


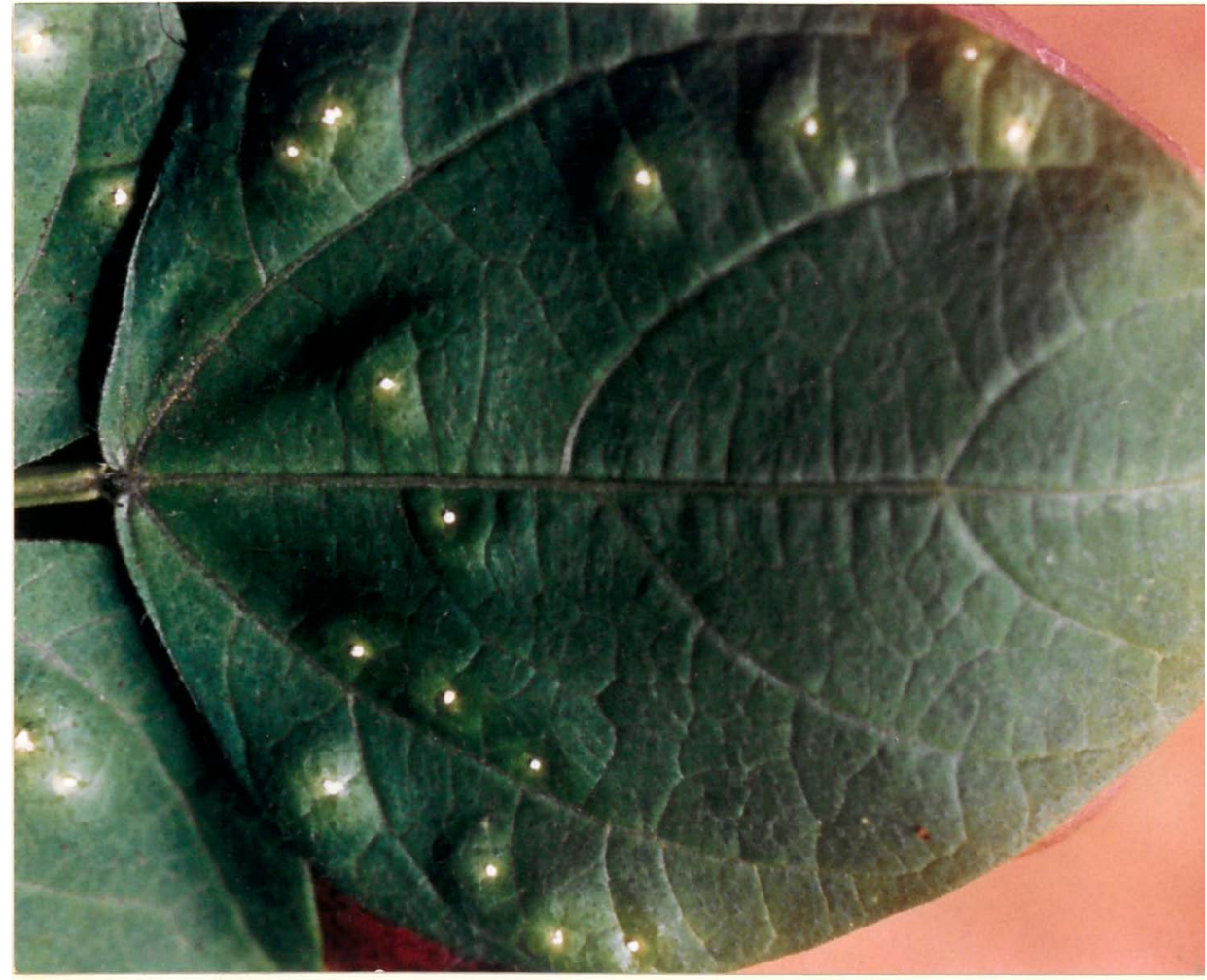

Figura 2. Folíolo de feijoeiro, após aplicação do cartap na fase de "fleck" da ferrugem, mostrando os pontos brancos e salientes, contituidos de uredosporos inviáveis. 
4.1.4. Ação preventiva do cartap sobre U. appendiculatus

Na aplicação do cartap com diferentes períodos antes da inoculação, o inseticida apresentou ação preventiva em todos os tratamentos estudados, diferindo estatisticamente do tratamento testemunha (Tabela 1). Todos os tratamentos que variaram de 24 a 144 horas antes da inoculação foram eficientes no controle preventivo da ferrugem. Assim, além dos fungicidas empregados preventivamente no controle da ferrugem do feijoeiro, como o oxycarboxin, chlorothalonil, bitertanol, triforine e mancozeb (ZAMBOLIM et al., 1985), os resultados obtidos indicaram que o inseticida cartap também proporcionou controle preventivo satisfatório de $U$. appendiculatus.

Tabela 1. Efeito preventivo do inseticida cartap sobre o número de pústulas de $U$. appendiculatus.

$\begin{array}{cl}\begin{array}{c}\text { Horas após aplicação } \\ \text { de cartap }\end{array} & \begin{array}{l}\mathrm{N} \text { c de pústulas } \\ \text { com uredosporos } \\ \text { normais }\end{array}\end{array}$

\begin{tabular}{crc}
\hline Testemunha & 202,68 a* \\
144 & 36,17 & $\mathrm{~b}$ \\
120 & 22,08 & $\mathrm{bc}$ \\
96 & 12,07 & $\mathrm{~cd}$ \\
72 & 6,90 & $\mathrm{de}$ \\
48 & 2,03 & $\mathrm{e}$ \\
24 & 1,62 & $\mathrm{e}$ \\
\hline
\end{tabular}
C.V. $(\%)=17,95$
D.M.S. $(5 \%)=2,02$

* Média de 20 folhas. Para a análise estatística, os dados foram transformados em $\sqrt{x}$. Médias seguidas por letras distintas diferem entre si (Tukey $5 \%$ ). 
Talvez a imperfeição na distribuição do cartap durante a pulverização proporcionou o desenvolvimento de algumas pústulas, porém estas apresentaram-se de tamanho bem menor em relação às do tratamento testemunha.

\subsubsection{Ação curativa do cartap sobre U. appendiculatus}

A investigação do efeito curativo mostrou que em todos os tratamentos com aplicação de cartap até cinco dias após a inoculação de $U$. appendiculatus, houve efeito curativo eficiente, com um controle acima de $80 \%$, ou seja, nota 6 . No tratamento testemunha a ferrugem desenvolveu-se normalmente (Figura 3). ZAMBOLIM et al. (1985) observaram efeito curativo com oxycarboxin e triforine quando aplicados mesmo seis dias após a inoculação e bitertanol e triadimefon três dias após a inoculação. Nenhuma informação sobre o efeito preventivo ou curativo apresentado pelo cartap sobre $U$. appendiculatus ou sobre qualquer outro patógeno foi encontrada na literatura. Trata-se portanto de resultado inédito para o conhecimento científico. 


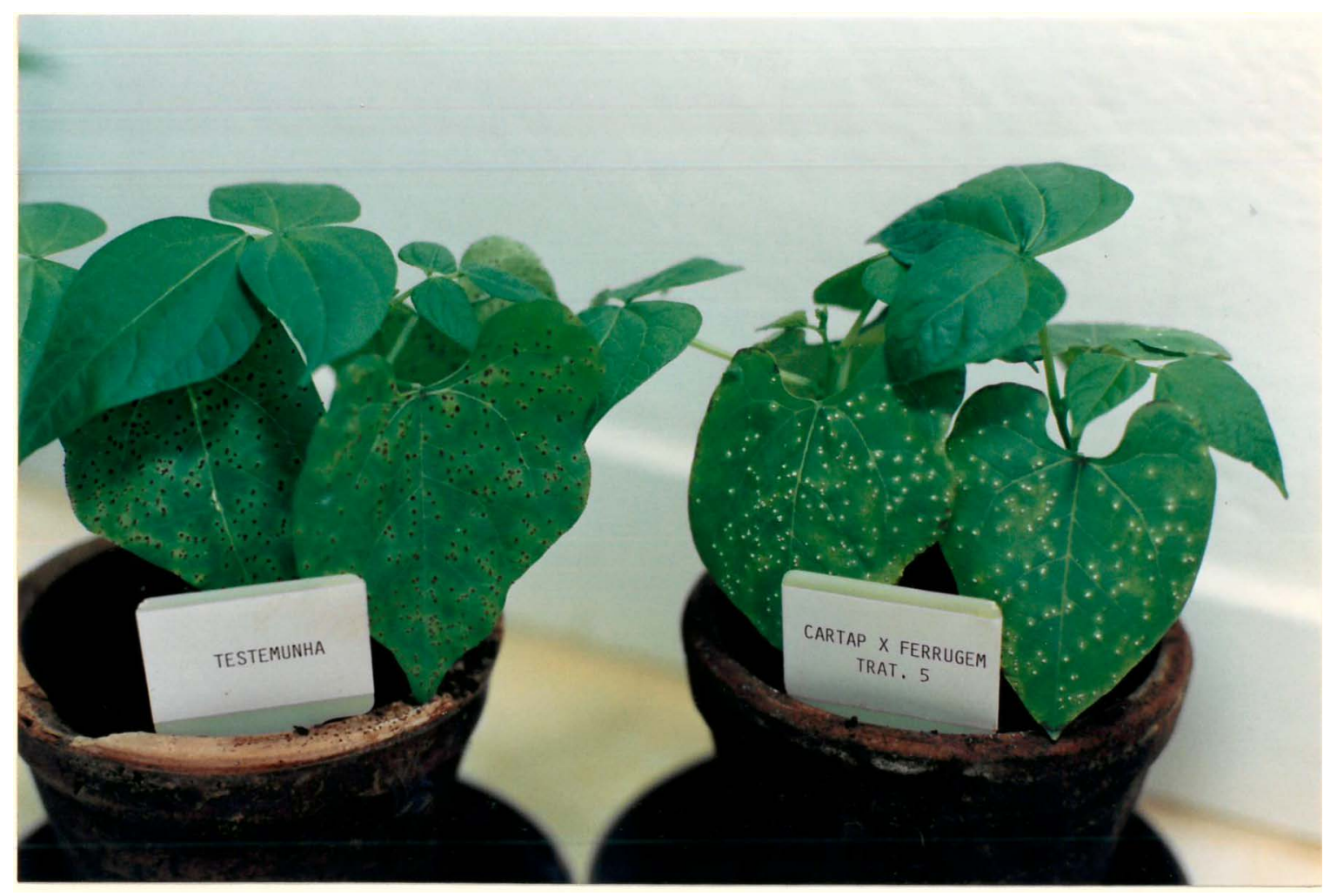

Figura 3. Efeito curativo do cartap sobre a ferrugem do feijoeiro. Desenvolvimento normal da ferrugem (Testemunha) e inviabilização dos uredosporos de $U$. appendiculatus (Trat. 5 ). 
4.1.6. Ação erradicante do cartap sobre U. appendiculatus, em associação com fungicidas

o inseticida cartap, aplicado isoladamente, apresentou a melhor ação erradicante comparando-se com os tratamentos em mistura. Apesar das misturas de cartap com mancozeb, hidróxido de trifenil estanho, tiofanato metílico + chlorothalonil, chlorothalonil, triforine e fertamin $M$ não diferirem estatisticamente de cartap isolado, observou-se que as pústulas apresentaram poucos uredosporos viáveis, enquanto que no tratamento somente com cartap, os uredosporos apresentaram-se brancos, isto é, inviáveis, até aos 14 dias após sua aplicação. A mistura que apresentou menor ação erradicante foi com o fungicida oxycarboxin. Este produto mostrou baixo efeito quando aplicado isoladamente. Os outros produtos, tiofanato metilico + chlorothalonil, mancozeb, hidróxido de trifenil estanho, fertamin $M$ e enxofre, foram iguais à testemunha, quando aplicados isoladamente (Tabela 2), não apresentando nenhum controle erradicante. Estes produtos são recomendados para o feijoeiro visando o controle das principais doenças da cultura (CASTRO et al., 1989; GOULART, 1990; CASTRO et al., 1991; OLIVEIRA et al., 1992), inclusive para a ferrugem.

Todavia, os resultados obtidos mostraram que somente o inseticida cartap controlou a ferrugem, quando esta 
já estava com os uredosporos maduros, marrons, no momento da aplicação dos produtos. Esta acão, sobre os uredosporos maduros, apresentada pelo inseticida cartap era até o momento desconhecida na literatura cientifica. Também, não foi encontrada na literatura qualquer informação sobre fungicidas com semelhante ação. Por outro lado, nenhuma das misturas mostrou efeito fitotóxico, indicando que cartap, na dosagem estudada, pode ser associado a outros produtos, com a finalidade de controlar várias doenças ao mesmo tempo. Somente as misturas com enxofre e oxycarboxin, aos sete dias após a aplicação, mostraram diferenças. Estes dois princípios ativos talvez tenham interferido na ação do cartap. Aos 14 dias após a aplicação, todas as misturas apresentaram menor efeito que o cartap isolado, porém sem efeito fitotóxico. 
Tabela 2. Efeito do inseticida cartap sobre $U$. appendiculatus em feijoeiro cv. Rosinha G-2, em associaçào com fungicidas, 7 e 14 dias após a aplicaçào.

\begin{tabular}{|c|c|c|c|c|}
\hline \multirow{2}{*}{ Tratamentos } & \multicolumn{4}{|c|}{ Notas } \\
\hline & \multicolumn{2}{|c|}{7 dias } & \multicolumn{2}{|c|}{14 dias } \\
\hline Cartap & $6,00 a$ & $a *$ & 6,00 & a \\
\hline Cartap + mancozeb & $6,00 a$ & & 5,24 & $\mathrm{~b}$ \\
\hline Cartap + hidr. trif. est. & $6,00 \therefore$ & & 5,24 & $\mathrm{~b}$ \\
\hline Cartap + tiof. met. + chloroth. & $6,00 \quad$ & & 5,00 & $\mathrm{~b}$ \\
\hline Cartap + chlorothalonil & $6,00 a$ & & 5,00 & $\mathrm{~b}$ \\
\hline Cartap + triforine & $6,00 \therefore$ & & 5,00 & $\mathrm{~b}$ \\
\hline Cartap + fertamin $M$ & $6,00 \therefore$ & & 5,00 & $\mathrm{~b}$ \\
\hline Cartap + enxofre & 5,00 & $\mathrm{~b}$ & 5,00 & $\mathrm{~b}$ \\
\hline Cartap + oxycarboxin & 3,00 & $\mathrm{C}$ & 3,00 & C \\
\hline oxycarboxin & 2,00 & d & 1,74 & $\mathrm{~d}$ \\
\hline Tiof.met. + chlorothalonil & 1,00 & e & 1,00 & e \\
\hline Triforine & 1,00 & e & 1,00 & e \\
\hline Chlorothalonil & 1,00 & e & 1,00 & e \\
\hline Mancozeb & 1,00 & e & 1,00 & e \\
\hline Hidróxido de trif. estanho & 1,00 & e & 1,00 & e \\
\hline Fertamin $M$ & 1,00 & e & 1,00 & e \\
\hline Enxofre & 1,00 & e & 1,00 & e \\
\hline Testemunha & 1,00 & e & 1,00 & e \\
\hline $\mathrm{C} \cdot \mathrm{V} \cdot\left(\frac{\circ}{6}\right)$ & 0,00 & & 2,45 & \\
\hline D.M.S. $(5 \%)$ & 0,00 & & 0,60 & \\
\hline
\end{tabular}

* Média de 16 folhas. Para análise estatistica, os dados foram transformados em arc sen $\sqrt{x / 100}$.

Médias seguidas por letras distintas, na coluna, diferem entre si (Tukey 5\%). 
4.2. Experimentos de Campo

4.2.1. Efeito fungicida do cartap sobre a ferrugem do feijão vagem

o melhor efeito preventivo sobre a ferrugem do feijão vagem foi obtido com o fungicida diniconazole, seguido de cartap - 100,0 g e cartap - 125,0 g, que não diferiram entre si. o fungicida diniconazole tem apresentado controle semelhante ou superior ao oxycarboxin para a ferrugem do feijoeiro (MANÇO, 1988). Cartap - 75,0 9, aplicado em intervalos de 7 e 14 dias, apresentou o mesmo efeito obtido com as aplicações semanais de oxycarboxin, não diferindo dos outros tratamentos com cartap (Tabela 3). A ação preventiva apresentada pelo cartap caracterizou-se pela formação de uredosporos inviáveis.

Todos os tratamentos com cartap apresentaram efeito erradicante sobre a ferrugem, sendo que os melhores foram os três tratamentos com aplicação semanal, que não diferiram estatisticamente entre si. O tratamento cartap 75,0 g aplicado a cada 14 dias apresentou efeito erradicante intermediário e os fungicidas diniconazole e oxycarboxin não mostraram efeito, no caso, sobre os uredosporos maduros (Tabela 4). 
Tabela 3. Efeito preventivo dos defensivos agrícolas sobre a ferrugem do feijão vagem.

\begin{tabular}{lccrc}
\hline Tratamentos & $\begin{array}{c}\text { Dosagens } \\
\text { (g } \begin{array}{l}\text { Intervalo de } \\
\text { aplicação } \\
\text { (dias) }\end{array}\end{array}$ & Notas \\
\hline Testemunha & - & - & 4,04 a* \\
Oxycarboxin & 75,0 & 7 & 2,04 & b \\
Cartap & 75,0 & 14 & 1,94 & b \\
Cartap & 75,0 & 7 & 1,90 & b \\
Cartap & 125,0 & 7 & 1,64 & bc \\
Cartap & 100,0 & 7 & 1,47 & bc \\
Diniconazole & 2,5 & 7 & 1,34 & c \\
\hline
\end{tabular}
C.V. $(\%)=12,25$
D.M.S. $(5 \%)=0,59$

* Média de 4 avaliações.

Médias seguidas por letras distintas diferem entre si (Tukey 5\%).

Tabela 4. Efeito erradicante dos defensivos agrícolas sobre a ferrugem do feijão vagem.

\begin{tabular}{lccc}
\hline Tratamentos & $\begin{array}{c}\text { Dosagens } \\
\text { (g.a./100 }\end{array}$ & $\begin{array}{c}\text { Intervalo de } \\
\text { aplicação Notas } \\
\text { (dias) }\end{array}$ \\
\hline Cartap & 125,0 & 7 & $5,90 \mathrm{a}$ \\
Cartap & 100,0 & 7 & $5,90 \mathrm{a}$ \\
Cartap & 75,0 & 7 & $5,88 \mathrm{a}$ \\
Cartap & 75,0 & 14 & $3,35 \mathrm{~b}$ \\
Diniconazole & 2,5 & 7 & $1,00 \mathrm{c}$ \\
Oxycarboxin & 75,0 & 7 & $1,00 \mathrm{C}$ \\
Testemunha & - & - & $1,00 \mathrm{C}$ \\
\hline
\end{tabular}

C.V. $(\%)=5,29$

D.M.S. $(5 \%)=0,42$

* Média de 2 avaliações.

Médias seguidas por letras distintas diferem entre si ( Tukey 5\%) 
De acordo com os resultados, o inseticida cartap mostrou ser promissor no controle preventivo e erradicante da ferrugem do feijão vagem. No caso, devendo-se observar que para o controle das pragas em todas as culturas para as quais cartap é registrado, o período de carência é de 14 dias até o início da colheita (ANDREI, 1990).

A avaliação da ferrugem efetuada durante o periodo da quarta colheita das vagens (sete dias após a pulverização), mostrou que o fungicida diniconazole apresentou o melhor controle nas vagens. Todos os tratamentos com cartap, aplicados semanalmente, não diferiram estatisticamente entre si, apresentando controle semelhante ao diniconazole (Tabela $5)$.

Quanto ao número total de vagens produzidas, não houve diferença estatistica. Todos os tratamentos foram iguais à testemunha (Tabela 6). Mesmo não diferindo estatisticamente dos demais produtos, a maior produtividade foi proporcionada pelo fungicida diniconazole. Os tratamentos com cartap, aplicados semanalmente e o oxycarboxin não diferiram entre si apresentando resultados estatisticamente iguais ao dinizonazole e à testemunha (Tabela 6). Projetando-se os dados para ton/ha, a diferença entre os quatro melhores tratamentos e o tratamento testemunha atinge de 7,5 a 2,6 ton/ha, diferença bastante significativa para os produtores. 
Tabela 5. Efeito dos defensivos agrícolas sobre a incidência da ferrugem nas vagens, na quarta colheita.

\begin{tabular}{lccrc}
\hline Tratamentos & $\begin{array}{c}\text { Dosagens } \\
\text { i.a./100 l) }\end{array}$ & $\begin{array}{c}\text { Intervalo de } \\
\text { aplicação } \\
\text { (dias) }\end{array}$ & $\begin{array}{c}\text { Vagens } \\
\text { c/ferrugem } \\
(\%)\end{array}$ \\
\hline Testemunha & - & - & 20,38 a* \\
Cartap & 75,0 & 14 & 8,25 b \\
Oxycarboxin & 75,0 & 7 & 3,51 bc \\
Cartap & 100,0 & 7 & 3,18 bc \\
Cartap & 125,0 & 7 & 3,13 bc \\
Cartap & 57,0 & 7 & 2,13 bc \\
Diniconazole & 2,5 & 7 & 0,53 c \\
\hline
\end{tabular}

C.V. $\left(\frac{\%}{6}\right)=28,99 \quad$ D.M.S. $(5 \%)=8,44$

Para a análise estatística, os dados foram transformados em $\operatorname{arc} \operatorname{sen} \sqrt{x / 100}$.

Médias seguidas por letras distintas diferem entre si ( Tukey 5\%) .

Tabela 6. Efeito dos defensivos agricolas na produção e peso de vagens de feijão vagem.

\begin{tabular}{|c|c|c|c|c|c|}
\hline \multirow{2}{*}{ Tratamentos } & \multirow{2}{*}{$\begin{array}{c}\text { Dosagens } \\
(\mathrm{g} \mathrm{i.a.l} \\
1001)\end{array}$} & \multirow{2}{*}{$\begin{array}{c}\text { Intervalo de } \\
\text { aplicação } \\
\text { (dias) }\end{array}$} & \multicolumn{3}{|c|}{ Produção } \\
\hline & & & 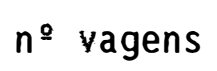 & peso(g) & ton/ha \\
\hline Diniconazole & $\begin{array}{r}2,5 \\
0\end{array}$ & $\begin{array}{l}7 \\
7\end{array}$ & $583,75 a$ & $5775,5 a$ & 23,1 \\
\hline Oxycarbox in & 75,0 & 7 & $468,75 a$ & $4485,0 a b$ & $\begin{array}{l}18,2 \\
17,9\end{array}$ \\
\hline Cartap & 75,0 & 7 & $466,50 a$ & $4452,5 \mathrm{ab}$ & 17,9 \\
\hline Cartap & 125,0 & 7 & $434,00 a$ & $4225,0 \mathrm{ab}$ & 16,9 \\
\hline Cartap & 75,0 & 14 & $432,50 a$ & $3912,5 \mathrm{ab}$ & 15,6 \\
\hline Testemunha & - & - & $428,75 a$ & $3892,5 \mathrm{~b}$ & 15,6 \\
\hline $\begin{array}{l}\text { C.V. (\%) } \\
\text { D.M.S. (5\%) }\end{array}$ & & & $\begin{array}{r}19,63 \\
216,68\end{array}$ & $\begin{array}{r}16,92 \\
1766,01\end{array}$ & \\
\hline
\end{tabular}

Médias seguidas por letras distintas, na coluna, diferem entre si (Tukey 5\%). 
o cultivo do feijão vagem, no Estado de são Paulo, está concentrado em Itatiba e municípios vizinhos, com semeaduras sucessivas. Este sistema favorece, na região, a manutenção de elevado potencial de inóculo de $U$. appendiculatus. No final de cada ciclo de cultivo, os agricultores cessam a aplicação de defensivos. Nesta fase, as folhas das plantas normalmente tornam-se repletas de soros com uredosporos de $U$. appendiculatus, aumentando assim o potencial de inóculo. As estacas de bambu utilizadas para a sustentação das plantas são reaproveitadas em muitas outras safras. No final do ciclo, estas estacas ficam totalmente contaminadas com os uredosporos de $U$. appendiculatus. Sabe-se que estes uredosporos podem sobreviver por aproximadamente 60 dias em condições adversas (CENTRO INTERNACIONAL DE AGRICULTURA TROPICAL, 1982), podendo assim ser disseminado por estas estacas para novas culturas.

$\mathrm{Na}$ ocorrência de condições favoráveis ao desenvolvimento da ferrugem, pode-se supor que os uredosporos aderidos às estacas constituem-se em fontes de inóculo primário, podendo até causar epidemias. MILBRATH (1944) observou que grande número de teliosporos ficava aderido às estacas utilizadas na cultura de feijão e ao serem reutilizadas em novas culturas, estas apresentavam, invariavelmente, infecções precoces, em relação aos campos com estacas novas. o autor conseguiu o controle através do mergulho das estacas contaminadas na mistura de cálcio-enxofre e sulfato de zinco. Os resultados obtidos com a aplicação do 
inseticida cartap evidenciam que este produto poderá ser muito importante na cultura do feijão vagem para o controle da ferrugem, controlando também os insetos minadores que têm causado grandes danos à cultura.

\subsubsection{Efeito fungicida do cartap sobre a ferrugem do feijoeiro, na safra das águas}

Na safra das águas, o inseticida cartap ensaiado na maior dosagem $(1,00 \mathrm{~kg} / \mathrm{ha})$ e aplicado semanalmente proporcionou o melhor controle da ferrugem, seguido da dosagem $0,75 \mathrm{~kg} / \mathrm{ha}$, também aplicado semanalmente (Tabela 7 ). Os demais tratamentos não diferiram estatisticamente deste tratamento, apresentando controle intermediário. Mancozeb não diferiu da testemunha e nem do chlorothalonil, porém este diferiu da testemunha e foi igual ao oxycarboxin.

Foi observado que em todos os tratamentos com cartap os uredosporos de $U$. appendiculatus tornaram-se brancos em maior ou menor quantidade nas pústulas, conforme o tratamento, confirmando assim a ação erradicante deste inseticida, observada nos experimentos anteriores. Esta ação erradicante, inviabilizando os uredosporos de $U$. appendiculatus, é uma propriedade muito importante do inseticida cartap. Ao agir sobre os uredosporos, que constituem

a principal forma de disseminação do patógeno (ZAUMEYER \& 
THOMAS, 1957; KIMATI, 1980), o inseticida proporciona a redução do potencial de inóculo na cultura ou até mesmo a sua eliminação, reduzindo ou eliminando os focos primários de infeç̧ão.

Tabela 7. Efeito dos defensivos agrícolas sobre a ferrugem do feijoeiro, cultivar Aroana 80 , na safra das águas.

\begin{tabular}{|c|c|c|c|c|}
\hline \multirow{2}{*}{$\begin{array}{l}\text { Tratamentos } \\
\text { Testemunha }\end{array}$} & \multirow{2}{*}{$\begin{array}{c}\text { Dosagens } \\
\begin{array}{c}(\mathrm{kg} \mathrm{i} \cdot \mathrm{a} \cdot / \mathrm{ha}) \\
-\end{array}\end{array}$} & $\begin{array}{c}\text { Intervalo de } \\
\text { aplicação } \\
\text { (dias) }\end{array}$ & \multicolumn{2}{|c|}{ Notas } \\
\hline & & - & 3,25 & $a *$ \\
\hline Mancozeb & 1,60 & 7 & 2,91 & $a b$ \\
\hline Chlorothalonil & 1,25 & 7 & 2,74 & bc \\
\hline oxycarboxin & 0,60 & 14 & 2,25 & cd \\
\hline Cartap & 0,50 & 14 & 2,10 & de \\
\hline Cartap & 0,75 & 14 & 2,09 & de \\
\hline Cartap & 0,50 & -7 & 1,94 & de \\
\hline Cartap & 1,00 & 14 & 1,93 & de \\
\hline Cartap & 0,75 & 7 & 1,71 & ef \\
\hline Cartap & 1,00 & 7 & 1,38 & $\mathrm{f}$ \\
\hline C.V. $(\%)=9,00$ & D.M.S & $(5 \%)=0,49$ & & \\
\hline
\end{tabular}

* Média de 80 folhas trifoliadas.

Médias seguidas por letras distintas diferem entre si (Tukey 5\%). 
Os principais fungicidas empregados no controle da ferrugem do feijoeiro como carboxin ou oxycarboxin (ZAMBOLIM \& CHAVES, 1978; BUJULU \& LOTASARWAKI, 1986; KIMATI, 1978; KIMATI et al., 1986), bitertanol (ZAMBOLIM et al. 1985; SANTINI, 1989; OLIVEIRA et al., 1992), etiltrianol (GOULART, 1990; SANTINI, 1989); chlorothalonil (ZAMBOLIM et al., 1985; CASTRO et al., 1989; CASTRO et al., 1991; TOMPKINS et al., 1983), diniconazole (MANÇO, 1988), mancozeb (SARTORATO et al., 1983; ZAMBOLIM et al., 1985) e triforine (BUJULU \& LOTASARWAKI, 1986; ZAMBOLIM et al., 1985) apresentam ação preventiva eficiente e pequena ação curativa, no controle da ferrugem. Tovadia não apresentam efeito sobre uredosporos maduros.

Um produto capaz de inviabilizar os uredosporos apresenta vantagens em relação a outros produtos, nesta fase do ciclo da doença, pois o controle da ferrugem pode ser obtido após o seu estabelecimento, além de reduzir ou eliminar a fonte de inóculo na cultura. o inseticida cartap foi o único produto que proporcionou este tipo de ação, o que evidencia a importância do produto no controle da ferrugem do feijoeiro, além de controlar a larva minadora (Agromyza sp. e Liriomyza sp.), denominada pelos agricultores de bicho mineiro.

O maior peso de 100 sementes foi proporcionado pelo fungicida mancozeb $(22,50 \mathrm{~g})$, sendo os outros tratamentos com $\circ$ inseticida cartap, além de chlorothalonil, intermediários, não diferindo de mancozeb (Tabela 8). 
Tabela 8. Efeito dos defensivos agrícolas sobre o peso de 100 sementes de feijão, cultivar Aroana 80 , na safra das águas.

\begin{tabular}{lccc}
\hline Tratamentos & $\begin{array}{c}\text { Dosagens } \\
(\mathrm{kg} \mathrm{i.a./ha)}\end{array}$ & $\begin{array}{c}\text { Intervalo de } \\
\text { aplicação } \\
\text { (dias) }\end{array}$ & $\begin{array}{c}\text { de } 100 \\
\text { sementes }\end{array}$ \\
\hline Mancozeb & 1,60 & 7 & $22,50 \mathrm{a}$ \\
Cartap & 1,00 & 7 & $21,75 \mathrm{ab}$ \\
Chlorothalonil & 1,25 & 7 & $20,75 \mathrm{ab}$ \\
Cartap & 1,00 & 14 & $20,75 \mathrm{ab}$ \\
Cartap & 0,75 & 14 & $20,50 \mathrm{ab}$ \\
Cartap & 0,75 & 7 & $20,25 \mathrm{ab}$ \\
Cartap & 0,50 & 7 & $20,00 \mathrm{ab}$ \\
Cartap & 0,50 & 14 & $19,75 \mathrm{ab}$ \\
Oxycarboxin & 0,60 & 14 & $18,75 \mathrm{~b}$ \\
Testemunha & - & - & $18,50 \mathrm{~b}$ \\
\hline
\end{tabular}

C.v. $(\%)=7,46$

D.M.S. $(5 \%)=3,70$

Médias seguidas por letras distintas diferem entre si (Tukey 5\%).

A avaliação do efeito do cartap na produtividade (Tabela 9) mostrou melhores resultados com os fungicidas mancozeb e cartap na maior dosagem $(1,0 \mathrm{~kg} / \mathrm{ha})$ aplicado a cada $14 \mathrm{dias}$, sendo $1.894,17$ e $1.844,15 \mathrm{~kg} / \mathrm{ha}$ respectivamente. Todos os outros tratamentos com cartap, oxycarboxin e chlorothalonil foram intermediários. 
Tabela 9. Efeito dos defensivos agrícolas sobre a produtividade do feijoeiro, cultivar Aroana 80 , na safra das águas.

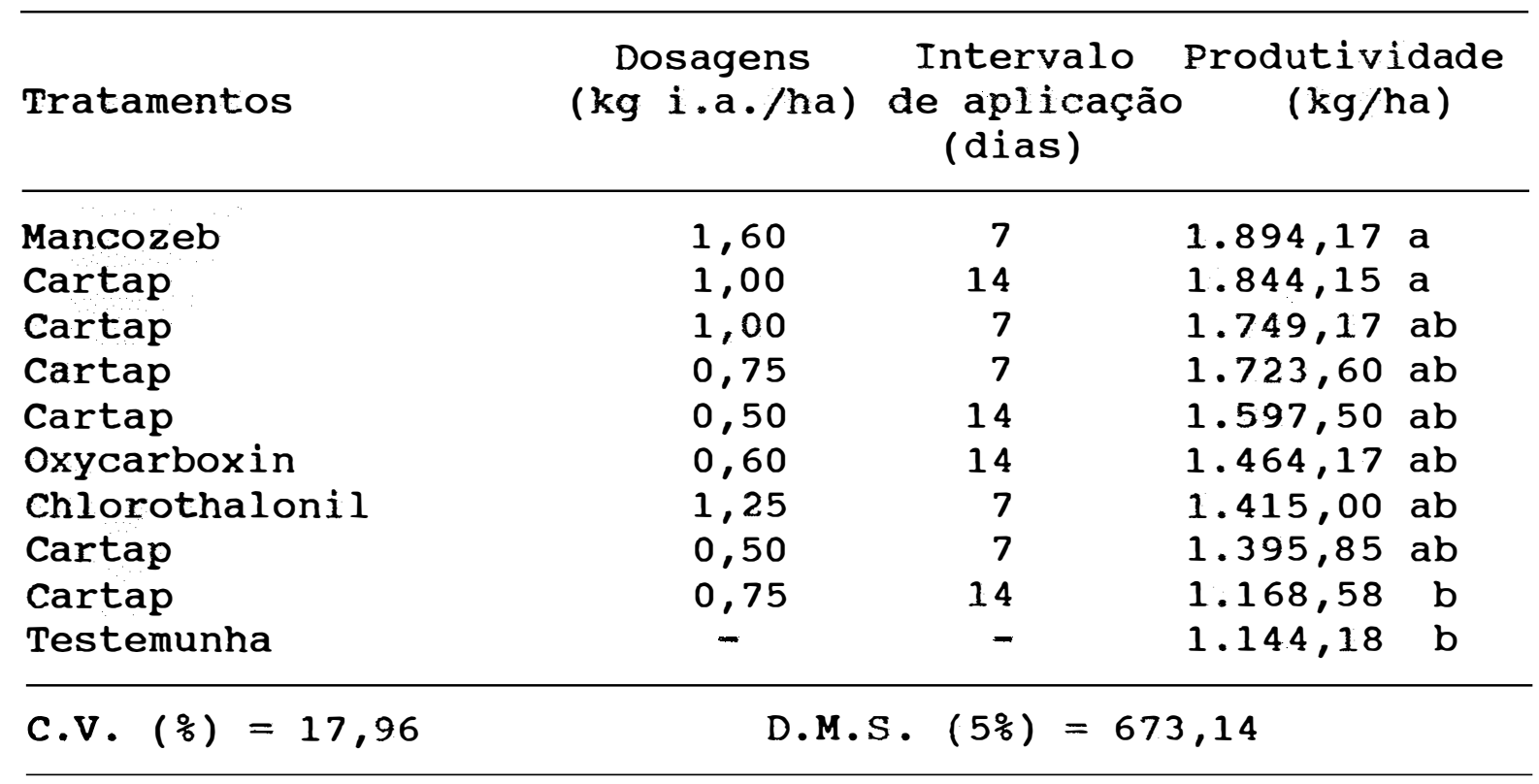

Médias seguidas por letras distintas diferem entre si (Tukey 5\%).

4.2.3. Efeito fungicida do cartap sobre a ferrugem do feijoeiro, na safra da seca

Na safra da seca, o inseticida cartap apresentou resultado semelhante quando comparado nas dosagens de 0,75 e $1,00 \mathrm{~kg} / \mathrm{ha}$ e aplicado semanalmente, proporcionando o melhor controle da ferrugem. No entanto, os tratamentos com oxycarboxin, triforine e cartap na dosagem de $1,0 \mathrm{~kg} / \mathrm{ha} e$ aplicado a cada 14 dias não diferiram estatisticamente destes tratamentos (Tabela 10). 
Tabela 10. Efeito dos defensivos agrícolas sobre a ferrugem do feijoeiro, cultivar Aroana 80 , na safra da seca.

\begin{tabular}{lcccc}
\hline Tratamentos & $\begin{array}{c}\text { Dosagens } \\
\text { (kg i.a./ha) }\end{array}$ & $\begin{array}{c}\text { Intervalo de } \\
\text { aplicação } \\
\text { (dias) }\end{array}$ & Nota \\
\hline Enxofre & 1,56 & 7 & 3,42 a* \\
Testemunha & - & - & 3,08 a \\
Chlorothalonil & 1,25 & 7 & 2,83 ab \\
Mancozeb & 1,60 & 7 & 2,42 & bc \\
Triforine & 0,28 & 7 & 2,08 & $\mathrm{~cd}$ \\
Cartap & 1,00 & 14 & 2,08 & $\mathrm{~cd}$ \\
Oxycarboxin & 0,60 & 7 & 1,92 & $\mathrm{~cd}$ \\
Cartap & 1,00 & 7 & 1,67 & $\mathrm{~d}$ \\
Cartap & 0,75 & 7 & 1,67 & $\mathrm{~d}$ \\
\hline C.V. $(\%)=11,01$ & & D.M.S. (5\%) & 0,62 & \\
\hline
\end{tabular}

* Média de 40 folhas trifoliadas.

Médias seguidas por letras distintas diferem entre si (Tukey 5\%) .

Nas duas safras, águas e seca, a ferrugem ocorreu com semelhante severidade, como pode ser observado nos tratamentos testemunha (Tabelas 7 e 10), sendo que na safra da seca os resultados confirmaram os dados obtidos na safra das águas, mostrando o melhor controle da ferrugem com o inseticida cartap.

Foi observado que muitos uredosporos tornaram-se brancos em todos os tratamentos com cartap, sendo assim 
inviabilizados, como nos experimentos anteriores, confirmando novamente esta importante propriedade, pois além de proporcionar segurança à cultura quanto às perdas devido à ferrugem, reduz o potencial de inóculo e a disseminação do patógeno, atuando exatamente na principal forma de sua disseminação, os uredosporos. Outra vantagem proporcionada pelo inseticida cartap poderá ser a redução do número de aplicações de defensivos agricolas, pois evidencia-se que o agricultor poderá iniciar o controle em qualquer época, mesmo após o estabelecimento da ferrugem.

oxycarboxin é um dos principais fungicidas recomendados para o controle da ferrugem do feijoeiro, desde a sua descoberta em 1966 (VON SCHMELING \& KULKA, 1966), com a sua eficiência comprovada em muitos trabalhos (VAUGAN \& SIEMER, 1967; BATES \& TWEEDY, 1971; FRENHANI et al ., 1971; YAMAMOTO et al., 1971; CAMPACCI et al., 1975; PAIVA et al ., 1976; NASSER et al., 1977; ROLIM et al., 1981a; BUJULU \& LOTASARWAKI, 1986). Na safra das águas e da seca, além do cartap, oxycarboxin foi o melhor fungicida no controle da ferrugem (Tabelas 7 e 10), concordando com estes trabalhos.

Os fungicidas chlorothalonil e mancozeb apresentaram o maior peso de 100 sementes, seguido de triforine e enxofre. 0 cartap nas dosagens de 0,75 kg/ha e 1,00 kg/ha, aplicados semanalmente, foram intermediários (Tabela 11). OLIVEIRA et al. (1992) observaram que acetato de trifenil estanho, chlorothalonil e tiofanato metilico + chlorothalonil 
foram os melhores fungicidas no aumento do peso de 100 sementes, nos experimentos realizados em Itapeva-SP e Capão Bonito-SP, assim como no experimento de ROLIM et al. (1981b), o chlorothalonil proporcionou maior peso de 1.000 grãos. Por outro lado, NASSER et al. (1977) não obtiveram diferenças entre - peso individual das sementes da testemunha e das parcelas tratadas com oxycarboxin, assim como RolIM et al. (1981a), que avaliaram vários fungicidas e não diferiram da testemunha.

Tabela 11. Efeito dos defensivos agrícolas sobre o peso de 100 sementes de feijão, cultivar Aroana 80, na safra da seca.

\begin{tabular}{lcccc}
\hline Tratamentos & $\begin{array}{c}\text { Dosagens } \\
(\mathrm{kg} i . \mathrm{a} \cdot / \mathrm{ha})\end{array}$ & $\begin{array}{c}\text { Intervalo } \\
\text { de } \\
\text { aplicação } \\
\text { (dias) }\end{array}$ & Peso (g) \\
\hline Chlorothalonil & 1,25 & 7 & $21,75 \mathrm{a}$ \\
Mancozeb & 1,60 & 7 & $21,75 \mathrm{a}$ \\
Triforine & 0,28 & 7 & $20,50 \mathrm{ab}$ \\
Enxofre & 1,56 & 7 & $20,00 \mathrm{abc}$ \\
Cartap & 0,75 & 7 & $18,25 \mathrm{bcd}$ \\
Cartap & 1,00 & 7 & 18,00 & bcd \\
Cartap & 1,00 & 14 & 17,25 & $\mathrm{~cd}$ \\
Oxycarboxin & 0,60 & 7 & 16,50 & $\mathrm{~d}$ \\
Testemunha & - & - & 15,75 & $\mathrm{~d}$ \\
\hline C.V. $(\%)=6,62$ & \multicolumn{5}{c}{ D.M.S. $(5 \%)=3,00$} & \\
\hline
\end{tabular}

Médias seguidas por letras distintas diferem entre si (Tukey 5\%). 
A maior produtividade foi obtida com o fungicida mancozeb porém, os produtos triforine, chlorothalonil e cartap na dosagem de $1,00 \mathrm{~kg} /$ ha e aplicado semanalmente não diferiram estatisticamente do mancozeb (Tabela 12). Talvez o estudo da associação de cartap com fungicidas que controlam as principais doenças do feijoeiro possa ser uma boa alternativa, para trazer soluções ao controle da mancha angular que, atualmente, se destaca no feijoeiro, pela dificuldade de controle.

Tabela 12. Efeito dos defensivos agricolas sobre a produtividade do feijoeiro, cultivar Aroana 80 , na safra da seca.

\begin{tabular}{|c|c|c|c|c|}
\hline \multirow{2}{*}{$\begin{array}{l}\text { Tratamentos } \\
\text { Mancozeb }\end{array}$} & \multirow{2}{*}{$\begin{array}{c}\begin{array}{c}\text { Dosagens } \\
(\mathrm{kg} \mathrm{i} \cdot \mathrm{a} \cdot / \mathrm{ha})\end{array} \\
1,60\end{array}$} & \multirow{2}{*}{$\begin{array}{l}\begin{array}{l}\text { Intervalo } \\
\text { de aplicação } \\
\text { (dias) }\end{array} \\
7\end{array}$} & \multicolumn{2}{|c|}{$\begin{array}{c}\text { Produtividade } \\
\text { (kg/ha) }\end{array}$} \\
\hline & & & $1,969,71$ & a \\
\hline Triforine & 0,28 & 7 & $1.678,23$ & $a b$ \\
\hline Chlorothalonil & 1,25 & 7 & $1.507,41$ & abc \\
\hline Cartap & 0,75 & 7 & $1.383,56$ & abcd \\
\hline Cartap & 1,00 & 7 & $1.248,46$ & bcde \\
\hline Enxofre & 1,56 & 7 & $1.212,32$ & bcde \\
\hline Cartap & 1,00 & 14 & 989,63 & cde \\
\hline Oxycarboxin & 0,60 & 7 & 823,27 & de \\
\hline Testemunha & - & - & 592,02 & e \\
\hline
\end{tabular}

Médias seguidas por letras distintas diferem entre si (Tukey 5\%). 
Como já mencionados, os principais fungicidas atualmente empregados no controle da ferrugem do feijoeiro, como chlorothalonil, triforine, carboxin ou oxycarboxin, diniconazole, etiltrianol, bitertanol, dentre outros, apresentam basicamente ação preventiva e pouca ação curativa a $U$. appendiculatus. Os resultados obtidos neste trabalho demonstraram as açōes preventiva, curativa e erradicante do inseticida cartap.

o desenvolvimento de um produto químico, até o emprego na agricultura, demanda muito tempo e grandes investimentos às empresas químicas, fatos que oneram o produto final, cujos custos são repassados aos agricultores. Esta descoberta, da eficiente ação do cartap sobre a ferrugem do feijoeiro, traz grandes benefícios aos agricultores e à sociedade, não somente pela eficiência no controle da ferrugem, mas também pelo baixo custo do produto. 


\section{CONCLUSŌES}

1. O inseticida cartap atua sobre os uredosporos de $U$. appendiculatus tornando-se brancos e inviáveis, ou seja, impedindo a sua capacidade de germinação;

2. o cartap tem ação preventiva, curativa e erradicante sobre a ferrugem do feijoeiro;

3. O inseticida cartap pode ser aplicado em qualquer época, mesmo após o estabelecimento da epidemia, impedindo o desenvolvimento de novos ciclos da ferrugem;

4. O inseticida cartap não altera o efeito de outros fungicidas, o que viabiliza o seu uso em mistura de tanque ;

5. A descoberta da ação do cartap sobre a ferrugem do feijoeiro possibilitará o estudo do seu mecanismo de ação e consequentemente a geração de novos produtos e de novas informações cientificas. 
REFERANCIAS BIBLIOGRÁFICAS

ANDREI, E. Compêndio de Defensivos Agrícolas. Guia prático de produtos fitossanitários para uso agrícola. $3^{\text {a }}$ ed. São Paulo, Organização Andrei Editora Ltda., 1980. 478p.

ANUÁRIO ESTATÍSTICO DO BRASIL - Fundação Instituto Brasileiro de Geografia e Estatística - IBGE, Rio de Janeiro, 51 : 512-3, 1991 .

BAIARDIN, R.S. Efeito de diferentes fungicidas no controle de Uromyces phaseoli (Reben) wint. e Erysiphe polygoni D.C. nas cultivares 'Carioca' e 'Goiano Precoce' de feijoeiro comum. In: REUNIÃO NACIONAL DEPESQUISA DE FEIJÃO, 4., Londrina, 1993. Resumos. Londrina, IAPAR, 1993. p.29.

BATES, J.J. \& TWEEDY, B.G. The effect of oxycarboxin on the bean rust disease caused by Uromyces phaseoli. In: ANNUAL MEETING OF THE AMERICAN PHYTOPATHOLOGICAL SOCIETY, 63, Phyladelphia, 1971. Abstracts. Phytopathology, Worcester, 61: 884,1971 .

BARROS, B.C. \& CASTRO, J.L. Efeito de aplicações de fungicidas no controle de doenças e rendimento do feijoeiro. In: SEMINÁRIO SOBRE PRAGAS E DOENÇAS DO FEIJOEIRO, 4, Campinas, 1991. Anais. Campinas, BARROS, B.C.; LEITE, L.G.; MENTEN, J.O.M., eds., 1991. p.21. 
BUJULU, J. \& LOTASARWAKI, J. Effect of fungicides and foliar fertilizers on bean rust. E. Agric. For. J., Tanzania, 52: $112-21,1986$.

CAMPACCI, C.A.; ROZANSKI, A.; CHIBA, S. Fungicidas para o controle da ferrugem (Uromyces phaseoli var. typica) do feijão-vagem (Phaseolus vulgaris L.). In: CONGRESSO DA SOCIEDADE BRASILEIRA DE OLERICULTURA, 15, Botucatu, 1975. Anais. Botucatu, 1975. p.233-4.

CASTELlane, P.D.; VIEIRA, R.D.; CARVALHO, N.M. Feijão-devagem (Phaseolus vulgaris L.): cultivo e produção de sementes. FCAV-UNESP, Jaboticabal, 1988. 60p.

CASTRO, J.L. Problemas fitossanitários do feijoeiro no estado de São Paulo: cultura das águas e da seca. In: SIMINÁRIO SOBRE PRAGAS E DOENÇAS DO FEIJOEIRO, 3, Campinas, 1988. Anais. Campinas, VENDRAMIN, J.D.; MENTEN, J.O.M.; LOURENÇÃO, A., eds., 1988. p.71-90.

CASTRO, J.L.; DUDIENAS, C.; ITO, M.F.; IGUE, T. Eficiência de fungicidas no controle de doenças do feijoeiro (Phaseolus vulgaris L.). Summa Phytopathologica, Jaguariúna, 15: 14555,1989 .

CASTRO, J.L.; ITO, M.F.; DUDIENAS, C.; BULISANI, E.A.; ALMEIDA, L. D'A. Ação de fungicidas sobre dois cultivares de feijoeiro em Capão Bonito-SP. Bragantia, Campinas, 50: $309-21,1991$.

CENTRO INTERNACIONAL DE AGRICULTURA TROPICAL. Enfermedades del fríjol causadas por hongos $y$ su control; guia de estudio para ser usada como complemento de la Unidad Audiotutorial sobre el mismo tema. Contenido Cientifico: SCHWARTZ, H.F. Producción: OSPINA, H.F. \& FOR, C.A. Cali, Colombia, CIAT. 56p. (Serie 04SB-01.01), 1982 . 
FANCELLI, A.L. Situação da cultura do feijão no estado de São Paulo. In: SEMINÁRIO SOBRE PRAGAS E DOENÇAS DO FEIJOEIRO, 3, Campinas, 1988. Anais. Campinas, VENDRAMIN, J.D.; MENTEN, J.O.M.; LOURENÇÃO, A., eds., 1988. p.17-21.

FRENHANI, A.A.; BULISANI, E.A.; ISSA, E.; SILVEIRA, S.g.P. Controle da ferrugem (Uromyces phaseoli var. typica Arth.) do feijoeiro (Phaseolus vulgaris L.) com fungicida sistêmico. O Biológico, São Paulo, 37: 25-30, 1971.

GOULART, A.C.P. Eficiência de fungicidas no controle de doenças do feijoeiro. Fitopatologia Brasileira, Brasília, 15: $86-8,1990$.

GROTH, J.V. \& MOGEN, B.D. Completing the life cicle of Uromyces phaseoli var. typica on bean plants. Phytopathology, St. Paul, 68: 1674-7, 1978.

ISSA, E. \& ARRUDA, H.V. Contribuição para o controle da ferrugem e da antracnose do feijoeiro. Arq. Inst. Biol., São Paulo, 31: 119-26, 1964 .

ITO, M.F.; YUKI, V.A.; DUDIENAS, C.; TANAKA, M.A.S. Controle da ferrugem do feijoeiro através do inseticida cartap, em condições de laboratório. In: SEMINÁRIO SOBRE PRAGAS E DOENÇAS DO FEIJOEIRO, 4, Campinas, 1991. Anais. Campinas, BARROS, B.C.; LEITE, L.G.; MENTEN, J.O.M., eds., 1991. p.20.

KIMATI, H. Fungicidas. In: GALLI, F., ed. Manual de

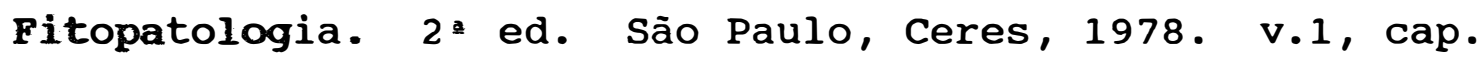
18, p.325-73. 
KIMATI, H. Doenças do feijoeiro. In: GALLI, F., coord. Manual de Fitopatologia. São Paulo, Ceres, 1980. v.2, p. 297-318.

KIMATI, H.; SOAVE, J.; ESKES, A.B.; KUROZAWA, C.; BRIGNANI NETO, F.; FERNANDES, N.G. FEIJÃO. In: GRUPO PAULISTA DE FITOPATOLOGIA, coord. Guia de fungicidas agrícolas. Piracicaba, Livroceres, 1986. cap. 70, p.116-21.

MANÇO, G.R. Diniconazole, um fungicida contra ferrugens. In: CONGRESSO BRASILEIRO DE FITOPATOLOGIA, 21, Salvador, 1988. Fitopatologia Brasileira, Brasilia, 13: 142, 1988.

MENDES, B.M.J. Influência da temperatura e do tipo de fol ha na quantificação de parâmetros epidemiológicos monocíclicos da ferrugem do feijoeiro (Uromyces phaseoli var. typica Arth.). Piracicaba, 1985. 83p. (Mestrado - Escola Superior de Agricultura "Luiz de Queiroz/USP).

MILBRATH, J.A. Studies on the control of bean rust. In: ANNUAL MEETING OF THE AMERICAN PHYTOPATHOLOGICAL SOCIETY, 27, Corvallis, 1944. Abstracts . Phytopathology, Lancaster, 34: 936, 1944 .

NASSER, L.C.B.; CHAVES, G.M.; ZAMBOLIM, L. Avaliação dos prejuizos causados por Uromyces phaseoli var. typica Arth. em diferentes estádios de desenvolvimento de duas variedades de feijão em função do método de aplicações de oxycarboxin. In: CONGRESSO BRASILEIRO DE FITOPATOLOGIA, 10 , Recife, 1977. Fitopatologia Brasileira, Brasilia, 2(1): 92, 1977. 
OLIVEIRA, S.H.F.; BARROS, B.C.; CASTRO, J.L. Avaliação do efeito de fungicidas no controle de doenças da parte aérea e na qualidade das sementes de feijoeiro. Summa Phytopatologica, Jaguariúna, 18: 178-84, 1992 .

PAIVA, F.A.; ZAMBOLIM, L.; CHAVES, G.M.; OLIVEIRA, L.M. Avaliação de fungicidas sistêmicos no controle da ferrugem do feijoeiro. In: CONGRESSO BRASILEIRO DE FITOPATOLOGIA, 9 , Campinas, 1976. Revista da Sociedade Brasileira de Fitopatologia, Campinas, 9: 7, 1976.

PURDY, L.H. Common and dwarf bunts, their chemical control in the Pacific Northwest. Plant Disease Reporter, Beltsville, 49: 42-6, 1965 .

RICHARDSON, L.T. Effect of insecticides and herbicides applied to soil on the development of plant diseases. II. Early blight and Fusarium wilt of tomato. Canadian Journal of Plant Science, Ottawa, 39: 30-8, 1959.

ROLIM, P.R.R.; BRIGNANI NETO, F.; ROSTON, A.J.; OLIVEIRA, D.A. Controle químico das doenças do feijoeiro. I. Ferrugem (Uromyces phaseoli (Pers.) wint. var. typica Arth.). O Biológico, São Paulo, 47: 201-5, 1981a.

ROLIM, P.R.R.; BRIGNANI NETO, F.; ROSTON, A.J.; OLIVEIRA, D.A. Controle químico das doenças do feijoeiro (Phaseolus vulgaris L.). III. Controle da antracnose em feijão das águas. O Biológico, São Paulo, 47: 245-8, 1981b.

SANTINI, A. Estudo do efeito de fungicidas no controle da ferrugem do feijão (Uromyces phaseoli var. typica Arth.). In: CONGRESSO BRASILEIRO DE FITOPATOLOGIA, 22, Recife, 1989. Fitopatologia Brasileira, Brasilia, 14: 145, 1989. 
SARTORATO, A.; RAVA SEIJAS, C.A.; YOKOYAMA, M. Princiopais doenças e pragas do feijoeiro comum no Brasil. Goiânia, EMBRAPA - CNPAF, 1983. 54p. (Documentos, 5).

SCHWARTZ, H.F. \& GALVEZ, G.E., eds. Problemas de produccion del frijol: enfermidades, insectos, limitaciones edafecas y climáticas de Phaseolus vulgaris. Cali, Colombia, Centro Internacional de Agricultura Tropical, 1980. 424p.

SCOTT, K.J. \& CHAKRAVORTY, A.K. The rust fungi. New York, Academic Press, 1982. 287p.

TANAKA, M.A.S.; ITO, M.F.; YUKI, V.A.; DUDIENS, C.; ALMEIDA Jr., A.R.; SUGIMORI, M.H.; PASSOS, F.A. Principais doenças da cultura do feijão vagem na região de Itatiba, SP. In: SEMINARIO SOBRE PRAGAS E DOENÇAS DO FEIJOEIRO, 4, Campinas, 1991. Anais. Campinas, BARROS, B.C.; LEITE, L.G.; MENTEN, J.O.M., eds., 1991. p.4.

TANAKA, M.A.S. \& JUNQUEIRA NETTO, A. Efeito de fungicidas sistêmicos sobre a intensidade de doenças da parte aérea e a qualidade sanitária da semente de feijão (Phaseolus vulgaris L.). Fitopatologia Brasileira, Brasilia, 7: 381-6, 1982 .

TOMPKINS, F.D.; CANARY, D.J.; MULLINS, C.A.; HILTY, J.W. Effect of liquid volume, spray pressure, and nozzle arrangement on coverage plant foliage and control of snap bean rust with chlorothalonil. Plant Disease, St. Paul, 67: 952-3, 1983 .

TYLER, L.J. \& JANSEN, N.F. SOil application of hexachlorobenzene and copper oxychloride for control of dwarf bunt. Plant Disease Reporter, Beltsville, 47: 197-9, 1963 . 
VAUGAN, E.K. \& SIEMER, S.R. Systemic chemical therapeutants for control of bean rust. In: ANNUAL MEETING OF THE AMERICAN PHYTOPATHOLOGICAL SOCIETY, California, 1966. Abstracts. Phytopathology, Worcester, 57: 103, 1967.

VIEIRA, C. Doenças e pragas do feijoeiro. Viçosa, UFV, Impr. Univ., 1983. 213p.

VON SCHMELING, B. \& KULKA, M. Systemic fungicidal activity of 1,4-oxathiin derivatives. Science, New York, 152: 659-60, 1966 .

YAMAMOTO, T.; CAMPACCI, C.A.; SUZUKI, U.; OI, A. Controle químico da ferrugem (Uromyces phaseoli (Reb.) wint. var. typica Arth.) do feijão vagem (Phaseolus vulgaris L.). In: REUNIÃO ANUAL DA SOCIEDADE DE OLERICULTURA DO BRASIL, 11 , Piracicaba, 1971. Resumos. Piracicaba, 1971. p.53-4.

YARWOOD, C.E. Therapeutic action of vapors from sulphur compounds. In: REPORT OF 1940 ANNUAL MEETING OF THE AMERICAN PHYTOPATOLOGICAL SOCIETY, Seatle, 1940. Abstracts. Phytopathology, Lancaster, 30: 791, 1940.

YARWOOD, C.E. The function of lime and host leaves in the action of bordeaux mixture. Phytopathology, Lancaster, 33 : $1146-56,1943$.

YARWOOD, C.E. The fungicidal value of mixtures of lime sulphur and zinc sulphate. Phytopathology, Lancaster, 37 : 852-3, 1947 .

YARWOOD, C.E. Therapeutic treatments for rusts. Phytopathology, Lancaster, 38: 542-51, 1948. 
ZAMBOLIM, L. \& CHAVES, G.M. Doenças do feijoeiro e seu controle. Informe Agropecuário, Belo Horizonte, 4: 49-63, 1978.

ZAMBOLIM, L.; RODRIGUES, C.H.; MARTINS, M.C. del P. Control of bean rust using protective systemic fungicides. Seiva, viçosa, 45: 1-16, 1985 .

ZAUMEYER, W.J. Field control of bean rust with sulphur. In: REPORT OF THE 1946 ANNUAL MEETING OF THE AMERICAN PHYTOPATOLOGICAL SOCIETY, New England, 1946. Abstracts. Phytopathology, Lancaster, 36: 689,. 1946.

ZAUMEYER, W.J. \& GOLDSWORTHY, M.C. Control of bean rust by fungicide dusting and spraying. In: ANNUAL MEETING OF THE AMERICAN PHYTOPATHOLOGICAL SOCIETY, 2, Beltsville, 1945. Abstracts. Phytopathology, Lancaster, 35: 489, 1945.

ZAUMEYER, W.J. \& THOMAS, H.R. A monografic study of bean diseases and methods for their control. Washington, U.S.D.A., 1957. 855p. (Technical Bulletin $n \cong 868$ ). 